\title{
THE CYANOGEN BROMIDE FRAGMENTS OF THE LARGE SUBUNIT OF RIBULOSEBISPHOSPHATE CARBOXYLASE FROM BARLEY
}

by

\author{
CARSTEN POULSEN \\ Department of Physiology, Carlsberg Laboratory \\ Gamle Carlsberg Vej 10, DK-2500 Copenhagen, Valby
}

Keywords: Fraction I, large subunit, chromatography, thin layer electrophoresis, trypsin, peptide maps, amino acid sequences, spinach.

The large subunit of ribulosebisphosphate carboxylase from barley has been subjected to cleavage with cyanogen bromide. The presence of 9 methionines among the about 490 amino acids in the polypeptide chain is expected to yield 10 fragments. Nine fragments have been identified and a tenth fragment was indicated in one cleavage experiment.

Six cleavage products have been purified by gel filtration on Bio-Gel P-30 and ion-exchange chromatography on carboxymethyl-cellulose and sulphopropyl-Sephadex. They have been characterized by amino acid composition, $\mathrm{N}$-terminal amino acid and tryptic peptide analysis. The $\mathrm{N}$-terminal amino acid and the approximate molecular weight of these six fragments are: Ala, 15,000 dalton; Pro, 10,000 dalton; PyrGlu, 7,000 dalton; Ser, 6,000 dalton; lle, 3,000 dalton; Pro, 2,000 dalton.

Two fragments (Arg, $\sim 4,500$ dalton and His, $\sim 4,500$ dalton) could not be separated. One fragment (Lys. 1.500 dalton) could not be purified, but was analyzed in mixture with the Pro-fragment of 2,000 dalton. The tenth fragment is indicated by an $\mathrm{N}$-terminal threonine together with the fragment having $\mathrm{N}$-terminal isoleucine. The two smallest $\mathrm{CNBr}$-fragments from barley have been sequenced and compared to the two smallest $\mathrm{CNBr}$ fragments obtained from the large subunit of the spinach enzyme. One of the spinach fragments was identical to the Lys-fragment from barley whereas the other was homologous to the lle-fragment from barley and revealed 3 amino acid differences between the two species.

Abbreviations: $\mathrm{CM}=$ carboxymethyl, DMAA $=\mathrm{N}, \mathrm{N}$-dimethyl-N-allylamine, $\mathrm{PITC}=$ phenylisothiocyanate, $\mathrm{PE}=$ pyridylethylated, $\mathrm{PTH}=$ phenylthiohydantoin, $\mathrm{SDS}=$ sodium dodecylsulphate, $\mathrm{SP}=$ sulphopropyl, TLC $=$ thin layer chromatography, TLE $=$ thin layer electrophoresis. 


\section{INTRODUCTION}

The major $\mathrm{CO}_{2}$-fixing enzyme in photosynthesizing organisms is D-ribulose-1,5-bisphosphate carboxylase (E. C. 4. 1. 1. 39). In algae and higher plants, this enzyme is localized in the stroma of the chloroplasts (9). The enzyme from eukaryotic species has a molecular weight of about 550,000 and accounts for up to 50 per cent of the total soluble leaf protein (43). Ribulosebisphosphate carboxylase from eukaryotes can be dissociated into two subunits with molecular weights of 55,000 and 12,000 15,000 respectively. Peptide mapping $(5,21)$ and characterisation by isoelectric focusing of the subunits from Nicotiana species and their $F_{1}$ hybrids $(22,31)$ as well as from Brassica species and their $F_{1}$ hybrids (40) have shown that the high molecular weight polypeptide (large subunit) is maternally inherited and that the low molecular weight polypeptide (small subunit) is biparentally inherited. Polymorphisms of the amino terminal amino acid sequences of the small subunit from the amphidiploid Nicotiana tabacum and its parental species, N. sylvestris and $\mathrm{N}$. tomentosiformis have revealed that the amphidiploid $\mathrm{N}$. tabacum has inherited two allelic nuclear genes coding for the small subunit, one from each parent species (36). The gene for the large subunit has been located on chloroplast DNA by cloning of restriction nuclease generated nucleotide sequences from the chloroplast DNA of Zea mays (7). One of the fragments could be transcribed and translated into the large subunit of the enzyme. Likewise, isolated messenger RNA for the large subunit of Chlamydomonas reinhardti hybridises with chloroplast DNA (12). The large subunit is synthesized on chloroplast ribosomes (4).

Determination of the primary structure of the large and the small subunits of ribulosebisphosphate carboxylase is a prerequisite for further analyses of the genetics, evolution and function of this enzyme (42). A statistical analysis of the amino acid compositions of the two subunits from a number of species indicated more variation for the small than the large subunit (38). Comparison of the primary structure of the $25 \mathrm{~N}$-terminal amino acids in 6 species has revealed allelic polymorphisms in 13 positions $(28,30,42)$. Four additional amino acids at the C-terminal end characterise the small subunit of the barley enzyme, when compared to that of spinach and tobacco $(28,42)$. For the large subunit from ribulose-bisphosphate carboxylase the sequences of three tryptic peptides, comprising 46 residues, are known. They were isolated after covalent modification with substrate analogue affinity labels (14). A comparison of corresponding cyanogen bromide fragments from barley and spinach have revealed four amino acid differences among 37 analysed residues $(29,42)$. Evidence that the gene for the large subunit in the chloroplast DNA is not completely conserved has also been obtained by chymotryptic peptide mapping of the large subunit from 9 genotypes of the genus Oenothera (17). The comparison included five different plastome types defined by their incompatibility relationships with nuclear genomes in interspecific crossings. Differences in peptide composition were observed among the genotypes, some of which correlated with a specific plastome type, whereas others did not. The Oenothera plastome types display minor differences in the physical map of chloroplast DNA as analysed with restriction nucleases (15).

Agarose gel electrophoresis of EcoRI restriction nuclease treated chloroplast DNA from populations of Nicotiana debneyi, revealed the absence of an EcoRl site in some of the populations (33). Variability of the chloroplast gene for the large subunit of ribulosebisphosphate carboxylase as well as for the organisation of chloroplast DNA is thus apparent and motivates a detailed amino acid sequence determination of the carboxylase. A brief summary of some of the data has been presented in (42).

\section{MATERIALS AND METHODS}

\subsection{Chemicals}

Unless otherwise specified chemicals were of analytical grade and used without further purification. 9 M urea was deionized on an ion exchange column immediately before use. Lyophilized tosyl-L-phenylalanine chloromethylketone treated trypsin (TPCK-trypsin) with an activity of 200 units $\cdot \mathrm{mg}^{-1}$ was obtained from Worthington, N. J., U.S.A. Three times recrystallized and lyophilized a-chymotrypsin and phenylthiohydantoin (PTH) amino acid derivati- 
ves was obtained from Sigma Chemical Co., Mo., U.S.A. Cyanogen bromide (CNBr) was from Fluka A.G., Buchs, Switzerland. Fluorescamine was from Hoffmann-LaRoche, Basel, Switzerland. N,N-dimethyl-4-amino-benzaldehyde (Ehrlichs reagent), 1-nitroso-napht-2-ol (tyrosine stain), 9,10-phenanthrenequinone (arginine stain), sulphanilic acid (histidine stain), ninhydrin, and Silicagel 60 precoated plastic thin layer plates and cellulose precoated glass thin layer plates were from Merck-Schuchardt, $\mathrm{Mu}$ nich, Germany. F-1700 polyamide thin layer plates were from Schleicher-Schüll A.G., Dassel, Germany. Phenylisothiocyanate (PITC) was from Kock-Light Laboratories, Colnbrook, England. Sodium dodecyl sulphate (SDS) of sequanal grade and $\mathrm{N}, \mathrm{N}$-dimethyl-N-allylamine buffer (0.4 M DMAA-trifluoroacetate in pyridine:water, 3:2 v/v) pH 9.5 was from Pierce Chemical Co., Rockford, Ill., U.S.A. SP-Sephadex C-25, Sepharose 6B, Sephadex G-100, G-50 and G-25 were from Pharmacia Fine Chemicals, Uppsala, Sweden. AG-501-X8 mixed bed ionexchanger for deionization of urea, Bio-Gel P-60, P-30 and P-4 were obtained from Bio-Rad Laboratories, Richmond, Calif., U.S.A. CMcellulose CM-52 was from Whatman, Maidstone, England.

\subsection{Equipment}

For gel filtration and ion-exchange chromatography columns from Pharmacia were used, whereas columns from Wright Scientific Ltd., Kenley, England were employed for the enzyme purifications. Eluates from columns were monitored for UV-transmission with LKB Uvicords II. Exponential gradients were generated by an LKB Ultrograd 11300 gradient mixer. UVabsorption of eluted fractions was measured in a Zeiss PMQ 3 spectrophotometer and gradients were measured in a conductivity meter from Radiometer, Copenhagen, Denmark.

\subsection{Enzyme purification and separation of subunits}

Ribulose bisphosphate carboxylase from barley was isolated and subunits separated as previously described (30), but with the following modifications. The plant material used was 200 $\mathrm{g}$ of 7 days old seedling leaves from the mutant ant 13-13 of Hordeum vulgare L. cv. Foma (20). This anthocyanin- and proanthocyanidinfree mutant yields more enzyme since precipitation by polyphenolic compounds is avoided. After the Sepharose 6B chromatography step, the enzyme gave only the two subunit bands upon SDS-polyacrylamide gel electrophoresis. The enzyme was precipitated with ammonium sulfate at $60 \%$ saturation. The pelleted crystals were redissolved at a concentration of $20 \mathrm{mg}$ per $\mathrm{ml}$ in Tris-buffer $\mathrm{pH} 7.8$ (buffer B) and dialyzed against this buffer. After dialysis, glycerol was added to a final concentration of $30 \%(\mathrm{v} / \mathrm{v})$ and the sample $(400 \mathrm{mg})$ was stored at $-18^{\circ} \mathrm{C}$ for later use. When needed, amounts of 150-250 mg were removed, dialyzed against destilled water and freeze dried.

Separation of the two subunits was carried out in $0.1 \mathrm{M}$-ammonium bicarbonate $\mathrm{pH} 8.5,0.5 \%$ SDS and $0.1 \% \mathrm{NaN}_{3}$ on a $9 \times 80 \mathrm{~cm}$ column of Sephadex G-100 Fine. Prior to separation the samples were flushed with $\mathrm{N}_{2}$ and reduced with $0.1 \mathrm{M}$-2-mercaptoethanol at $40^{\circ} \mathrm{C}$ for one hour. If required the protein was modified by $S$ carboxymethylation (16) or S-4-pyridylethylation (11). After separation SDS was removed by dissolving the subunit in 1 volume $10 \mathrm{mM}-\mathrm{HCl}$ and thereafter precipitating the protein with 4 volumes of acetone (30).

\subsection{Cyanogen bromide cleavage}

Cyanogen bromide cleavage of large subunit samples was performed in $70 \%$ formic acid according to SteERs et al. (35) at a protein concentration of $10 \mathrm{mg}$ per $\mathrm{ml}$. A 100-150 fold molar excess of $\mathrm{CNBr}$ over methionine was added. The reaction was proceeding for 24 hours at room temperature. At this stage the protein suspension had cleared completely and was diluted 10 -fold with destilled water and subsequently dried over solid $\mathrm{NaOH}$ in an evacuated desiccator.

\subsection{Gel filtration and ion-exchange chromatography of CNBr-fragments}

Three approaches for the purification of the CNBr-fragments were used: 1) A mixture of formic acid, acetic acid and water in a ratio of 
1:1:2 by volumes proved optimal for gel filtration of S-4-pyridylethylated and $\mathrm{CNBr}$ fragmented large subunit. This mixture minimized the content of formic acid, needed for solubilization of the fragments and did not boil during evacuation for drying. Bio-Gel P-30 (100-200 mesh) and P-60 (100-200 mesh) were chosen for gel filtrations. The columns were freshly made every fourth month. On such columns $(2,5 \times 85 \mathrm{~cm})$ samples containing between 50 and $0.5 \mathrm{mg}$ of $\mathrm{CNBr}$-fragments could routinely be chromatographed.

2) Cation-exchange chromatography in $8 \mathrm{~m}$ urea according to Fowl.ER ( 10$)$ was applied as a primary means of separation. Exponential gradients of $\mathrm{NaCl}$ were applied to the $\mathrm{CM}$-cellulose column for elution. Two samples of 35 and 155 mg respectively of $\mathrm{CNBr}$-fragmented S-4-pyridylethylated large subunit were chromatographed. After desalting of fragment peaks on columns of Sephadex G-25 and G-50 Superfine the fragments were chromatographed on the P-30 or P-60 columns. After drying of the eluates $1 \mathrm{ml}$ of $0.1 \mathrm{M}$-ammonium hydroxide was added to individuals tubes, which were successively analyzed for content of peptide material. Appropriate fractions were pooled and freeze dried, and the gel filtration on the Bio-Gel P-30 and P-60 columns repeated until homogenous samples were achieved.

3) In a third approach the CNBr-fragments were first separated according to molecular size and thereafter by charge differences. Four $35 \mathrm{mg}$ samples of $\mathrm{CNBr}$-fragmented S-carboxymethylated large subunit were chromatographed on a column of Bio-Gel P-30. Appropriate sizeclasses of $\mathrm{CNBr}$-fragments were pooled and subjected again to gel filtration and thereafter to cation-exchange chromatography. For the latter the CM-cellulose system mentioned above or a system of SP-Sephadex C-25 in 8 M-urea and 20-50mM-ammonium formiate $\mathrm{pH} 3.6$, or SPSephadex C-25 at $50^{\circ} \mathrm{C}$ was used in $30 \%$ acetic acid adjusted to $\mathrm{pH} 2.45$ with pyridine. Elution was performed with exponential $\mathrm{NaCl}$ gradients and the eluted peptide peaks were desalted and freeze dried.

\subsection{Sodium dodecyl sulfate polyacrylamide gel electrophoresis}

Gel electrophoresis was run under denaturing conditions on $1 \mathrm{~mm}$ thick analytical slab gels, using the discontinuous alkaline buffer system of Neville (25). Electrophoresis of pure enzyme and of subunit preparations were run on either 10 or $12.5 \%$ gels, whereas the purity of larger CNBr-fragments was evaluated on $15 \%$ gels. The experimental details were otherwise as described by Chua and Bennoun (6).

\subsection{Amino acid analysis}

Amino acid composition of $\mathrm{CNBr}$-fragments were determined as follows. Fragment samples were hydrolyzed in evacuated ampoules with $6 \mathrm{~N}-\mathrm{HCl}$ containing $0.1 \%$ phenol for 24 hours at $110^{\circ} \mathrm{C}$, dried and analyzed on a Durrum D-500 analyzer. Of the CNBr-methionine derivatives homoserine elutes from the analyzer immediately before glutamate and homoserine lactone immediately after histidine. For quantitation of ninhydrin color the coefficient for glutamate was used with homoserine and a coefficient half of that of glutamate with the lactone. When pure fragments were analyzed, one equivalent of homoserine plus homoserine lactone was used to calculate an approximate amino acid composition, from which a better composition having as many whole-number or close to whole-number values could be obtained. When mixtures of two fragments were analyzed. two equivalents of homoserine plus homoserine lactone was used for this estimation. Amino acid compositions of the large subunit were determined from triplicate $25 \mu \mathrm{g}$ samples hydrolyzed as above for 24,48 and 72 hours. The values for threonine, tyrosine and serine were obtained after extrapolation to zero time, whereas values for valine and isoleucine were those obtained after 72 hours of hydrolysis. For the analysis of cysteine and methionine, samples containing 25 $\mu \mathrm{g}$ of either performic acid oxidized, S-carboxymethylated or S-pyridylethylated protein were hydrolyzed for 24 hours. Tryptophan was determined by the spectrophotometric method of BENCZE and SCHMID (2) using an absoption coefficient determined for the maximum at 280 $\mathrm{nm}(1)$. 


\subsection{Dansylation and identification of $\mathbf{N}$ - terminal amino acid residues}

Identification of $\mathrm{N}$-terminal amino acid residues, using the dansylation technique as described by Hartley (13), was carried out with half the amount of polypeptide material used for amino acid analysis. Duplicate samples were hydrolyzed, one for four to six hours, and the other for 16-20 hours. After hydrolysis, dansylated amino acids were identified by two dimensional thin layer chromatography (TLC) on $5 \times 5 \mathrm{~cm}$ or $7.5 \times 7.5 \mathrm{~cm}$ polyamide layers, using the three solvents described by HARTLEY (13) for identification of the neutral amino acid derivatives and double-labelled lysine. On one plate dansyl-aspartate and dansyl-glutamate were identified by additional chromatography in the second dimension using butylacetate:methanol:acetic acid $(30: 20: 1), \mathrm{v} / \mathrm{v})$ as a solvent. On the other plate dansyl-histidine was separated from dansyl-arginine and $\varepsilon$-dansyl-lysine with pyridine acetate $\mathrm{pH} \quad 4.4$ (pyridine:acetic acid:water; 9:16:1000,v/v):ethanol $(3: 1, \mathrm{v} / \mathrm{v})$ in the second dimension (HOLDER; pers. commun.). Dansyl-arginine and $\varepsilon$-dansyl-lysine were separated on the same plate by running $50 \mathrm{~mm}$ $\mathrm{Na}_{3} \mathrm{PO}_{4}$ :ethanol $(3: 1, \mathrm{v} / \mathrm{v})$ in the direction opposite to that used in the first dimension (HOLDER, pers. commun.).

\subsection{Edman degradation procedures}

The manual dansyl-Edman procedure described by HaRtLEy (13) was used on $100 \mathrm{nmol}$ quantities of some small fragments. The following modifications were introduced: Coupling of PITC to the peptides was undertaken in $200 \mu \mathrm{l}$ of DMAA-trifluoroacetate buffer $\mathrm{pH} 9.5$, in which the peptides were dissolved. After 15 minutes coupling at $50{ }^{\circ} \mathrm{C}$, the reaction mixture was rapidly chilled and extracted with $1 \mathrm{ml}$ of benzene containing $0.1 \%$ 2-mercaptoethanol. All handling was done in a stream of nitrogen. Volumes of the coupling buffer were decreased from step to step, corresponding to the amount removed for dansylation between the degradation steps. The dansylation procedure was followed as described (cf. 2.8), except that only one sample was analyzed and the butylacetate solvent system was omitted. The anilinothiazolinone-derivative of the removed $\mathrm{N}$-terminal amino acid was extracted with butylacetate, hydrolyzed with $57 \% \mathrm{HI}$ and subjected to amino acid analysis (34).

Edman degradation with identification of PTH derivatives was performed essentially as described by Peterson et al. (26). PTH derivatives were identified by two dimensional separation on $7.5 \times 7.5 \mathrm{~cm}$ polyamide thin layers as described by Summers et al. (37). Some of the samples were further characterized by amino acid analysis after hydrolysis in $57 \% \mathrm{HI}$, as described by INGLIS et al. (18).

\subsection{Digestion with proteolytic enzymes}

In general, digestion with trypsin, $\alpha$-chymotrypsin and subtilisin type Carlsberg, (kindly provided by Dr. I. SVENDSEN), were performed in 0.1 $\mathrm{M}$-ammonium bicarbonate $\mathrm{pH} 7.8$ at $37^{\circ} \mathrm{C}$, for two or three hours. Trypsin was dissolved in 10 $\mathrm{mm}-\mathrm{HCl}$, whereas the two other enzymes were dissolved in $0.1 \mathrm{M}$-ammonium bicarbonate immediately before use. The enzyme concentrations were $0.5 \mathrm{mg} \cdot \mathrm{ml}^{-1}$. The $\mathrm{CNBr}$-fragments to be used (10-100 nmoles) were dissolved in the buffer at a concentration of 1 nmole per $10 \mu \mathrm{l}$. The volumes of the added enzyme was $5 \mu l(0.1$ nmole) per 10 nmoles of peptide. The digestions were stopped adding glacial acetic acid until all bicarbonate had been removed as $\mathrm{CO}_{2}$. Subsequently, digests were separated in an appropriate number of tubes for peptide mapping and then dried.

\subsection{Peptide mapping procedures}

Tryptic digests of 10-15 nmoles of two intermediary size fragments were subjected to twodimensional thin layer chromatography as described by HOLDER (17) with the following alterations: Three 3-4 nmole samples from each digest were dissolved in $5 \mu \mathrm{l}$ of $0.05 \mathrm{~m}$-pyridine acetate $\mathrm{pH} 2.45$ and applied in the corner, $1 \mathrm{~cm}$ from the two edges, of a $10 \times 10 \mathrm{~cm}$ plate of silica gel, and chromatographed in isopropanol:acetid acid:water:ethanol $(3: 1: 1: 1, \mathrm{v} / \mathrm{v})$ (Solvent $\mathrm{A})$ and in butanol:acetic acid:water: pyridine:methanol (45:6:24:20:30, v/v) (Solvent B). An amino acid reference mixture was run along the edge opposite to that used for the sample in the first dimension. A new aliquot of 
reference mixture was separated in the second dimension along the edge opposite to the sample application point. Subsequently, amino acid specific staining procedures were employed as described by HOLDER (17).

Tryptic digests of four samples, containing the two largest fragments, being either S-carboxymethylated or S-4-pyridylethylated were subjected to thin layer electrophoresis and thin layer chromatography in the first and second dimensions, respectively. Three 10 nmole samples from each of the four digests were applied in 10 $\mu \mathrm{l}$ of pyridine acetate $\mathrm{pH} 2.45$ to prewashed (19) $20 \times 20 \mathrm{~cm}$ glass plates precoated with cellulose. The samples were applied 14 and $6 \mathrm{~cm}$ from the cathode and anode edges, respectively, and $3 \mathrm{~cm}$ from the edge in the direction of electrophoresis. A sample of the amino acid reference mixture was applied in a similar way at the opposite edge. Subsequently, the plate was wetted with electrophoresis buffer in such a way that the buffer approached and sharpened the sample spots from both sides. Excess buffer was gently soaked away with filter paper. Horizontal electrophoresis with water cooling $\left(15^{\circ} \mathrm{C}\right)$ was applied for one hour at $700 \mathrm{~V}$ and $40 \mathrm{~mA}$. The electrophoresis buffer was pyridine acetate $\mathrm{pH}$ 4.4 (pyridine:acetic acid:water:acetone (20:40: 790:150, v/v)) (32).

The plates were dried in a stream of hot air and an aliquot of the marker mixture was applied two $\mathrm{cm}$ from one of the electrode ends (cf. Figure 13). After this, ascending TLC was run in the second dimension. The chromatography solvent was butanol:acetic acid: water:pyridine $(45: 6: 24: 20, \mathrm{v} / \mathrm{v})(3)$.

After chromatography to $1 \mathrm{~cm}$ from the upper edge, the thin layers were dried at $55{ }^{\circ} \mathrm{C}$ overnight. Subsequently, the plates were sprayed with the fluorescamine reagent (23). The plates were examined under UV-light at $366 \mathrm{~nm}$ for fluorescent spots.

One plate from each set of digest was used for the cadmium ninhydrin stain to see the correspondence between the two reagents. This was followed by Ehrlichs reagent staining for tryptophan (8).

Six 15-20 nmole samples of a tryptic digest of a mixture of two intermediary size fragments, and three 15 nmole samples of a tryptic digest of a mixture of two smaller fragments were subjected to the same procedure. The two smallest fragments, one of them in purified form, was partially characterized by digestion with trypsin, chymotrypsin and subtilisin. These digests were subjected to gel filtration on Bio-Gel P-4 (200-400 mesh) in 0.1-M-ammonium bicarbonate, followed by thin layer chromatography of aliquots of fractions on silica gel (cf. legend to Figure 18).

\subsection{Analysis of tryptic peptides from the CNBr-fragments}

Fluorescamine positive spots on the cellulose thin layer chromatograms of tryptic digests of six CNBr-fragments, two in purified form and four in mixtures of two, were analysed in the following way. The spots, encircled with a soft pencil, were scraped loose and gently sucked into a pasteur pipette containing a glass wool plug with the aid of a water pump connected to the tipped end of the pipette. Individual peptides were collected from two to five chromatograms in this way. Each pipette was placed in a $12 \times$ $100 \mathrm{~mm}$ test tube, and the cellulose eluted with four $0.5 \mathrm{ml}$ aliquots of $0.05 \mathrm{~m}$-pyridine acetate buffer, $\mathrm{pH}$ 2.45. The samples were dried and redissolved in $350 \mu \mathrm{l}$ of $0.1 \mathrm{M}-\mathrm{NH}_{4} \mathrm{OH} .200 \mu \mathrm{l}$ was removed and dried in a $8 \times 70 \mathrm{~mm}$ tube for amino acid analysis and 100-150 $\mu$ in tubes for dansylation. Amino acid analysis and dansylanalysis was carried out as described in 2.7 and 2.8 .

\subsection{Designations for cyanogen bromide fragments}

Fragments obtained by cyanogen bromide cleavage are designated with the letters $C B$. To this is added the letter $\mathrm{P}$, if the subunit had been $\mathrm{S}-4$ pyridylethylated or the symbol Cam if the subunit had been S-carboxymethylated. Roman numerals indicate the order of appearance of the fragments from gel filtration columns. Fragments separated by ion exchange columns are designated with CM if a CM-cellulose column is used and with SP if a SP-Sephadex column is employed. They are numbered with arabic numerals in order of elution. After the final purifications and identifications the $\mathrm{CNBr}$-fragments are designated by the $\mathrm{N}$-terminal amino acid and molecular weight. 
The following is a key to the ten fragments: Ala-fragment of 15,000 dalton: $\mathrm{CBP}-\mathrm{CM} 2-$ I = CBCam-IISP1 = CBCam-IISP2

Pro-fragment of 10,000 dalton: $\mathrm{CBP}-$ $\mathrm{CM} 1=\mathrm{CBCam}-\mathrm{IISP} 4=\mathrm{CBP}-\mathrm{CM} 4=\mathrm{CBP}-$ CM5; CBP-CM5X

PyrGin-fragment of 7,000 dalton: $\mathrm{CB}-$ $\mathrm{III}=\mathrm{CBP}-\mathrm{CM} 6=\mathrm{CBP}-\mathrm{CM} 7=\mathrm{CBCam}-$ IIISP1

Ser-fragment of 6,000 dalton: CBP-CM2II = CBCam-IIISP2

Arg-fragment of $\sim 4,500$ dalton: $\mathrm{CBCam}-$ IV = CBCam-IVSPI = CBCam-IVSP2 $=\mathrm{CBCam}-\mathrm{IVCM} 1=\mathrm{CBCam}-\mathrm{IVCM} 2$

His-fragment of $\sim 4,500$ dalton: as for Argfragment

Ile-fragment of $\sim 3,000$ dalton: $\mathrm{CBP}-$ CM8 = CBCam-V; CBCam-VSP 1; CBCamVSP2

Thr-fragment: Not separated from Ile-fragment

Pro-fragment of 2,000 dalton: CBP-CM3

$=\mathrm{CBCam}-\mathrm{VISP} 1=\mathrm{CBCam}-\mathrm{VISP} 2$; CBP VI

Lys-fragment of 1,500 dalton: CBP-VI
Table I

Amino acid composition of Ribulose bisphosphate carboxylase large subunit from barley.

\begin{tabular}{lcc}
\hline & $\begin{array}{c}\text { Mole } \\
\text { percentage }\end{array}$ & $\begin{array}{c}\text { Residues } / 55,000 \\
\text { molecular weight }\end{array}$ \\
\hline Cys & 1.74 & 9 \\
Asx & 8.95 & 44 \\
Thr & 6.01 & 30 \\
Ser & 3.79 & 19 \\
Glx & 9.75 & 48 \\
Pro & 4.53 & 22 \\
Gly & 9.93 & 49 \\
Ala & 9.57 & 47 \\
Val & 6.58 & 32 \\
Met & 1.78 & 9 \\
Ile & 4.70 & 23 \\
Leu & 8.32 & 41 \\
Tyr & 3.22 & 16 \\
Phe & 4.35 & 21 \\
His & 2.96 & 15 \\
Lys & 5.36 & 26 \\
Arg & 5.96 & 29 \\
Trp & 2.48 & 12 \\
\hline Total & 100.00 & 492 \\
\hline
\end{tabular}

large $\mathrm{CNBr}$-fragments were consistently present as three strongly staining bands (III) whereas the smaller CNBr-fragments (IV) follow the bromphenolblue front marker. A group of weakly staining bands (II) varied in amount from experiment to experiment and thus could result from incomplete $\mathrm{CNBr}$-cleavage.

\subsection{Gel filtration of the $\mathrm{CNBr}$-fragments}

Gel filtration of the $\mathrm{CNBr}$-fragments resulted in 6 peaks, designated I to VI, irrespective of whether the large subunit had been modified at the cysteines or not (Figures 2 and 3). SDSpolyacrylamide gel electrophoresis revealed peak II to contain the three large $\mathrm{CNBr}$-fragments (cf. Figure 1, III). Peak I contained the weakly staining polypeptides (Figure 1, II) and an aggregated form of one of the fragments in peak II. Peak I is especially large when unmodified large subunit is used (Figure 3). Its content becomes distributed to a considerable extent between peaks II and IV if the large subunit has been modified (Figure 2), suggesting that the 


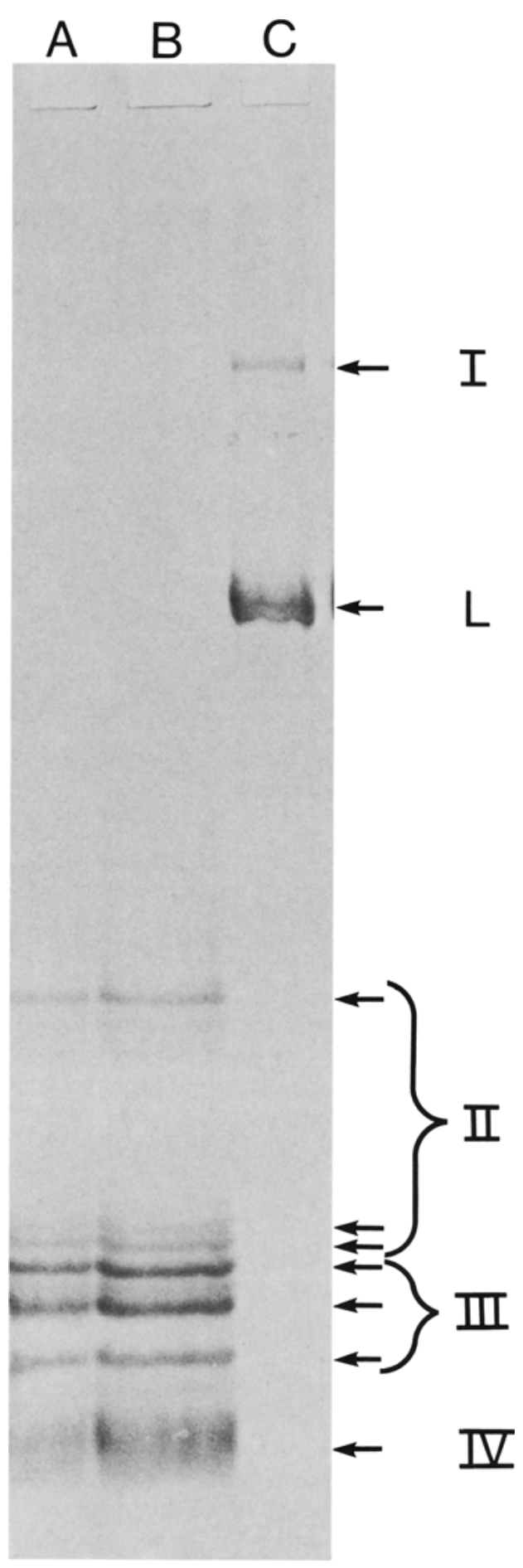

Figure 1. SDS-polyacrylamide gel electrophoresis of barley ribulose bisphosphate carboxylase large subunit and the mixture of fragments produced by cleavage of the large subunit with cyanogen bromide. A: $30 \mu \mathrm{g}$ of fragments; B: $60 \mu \mathrm{g}$ of fragments; C: 25 $\mu \mathrm{g}$ of large subunit. Experimental conditions were as described under 2.6 using a $7.5-15 \%$ polyacrylamide gradient gel. $\mathrm{L}=$ large subunit; $\mathrm{I}=$ Dimer of large subunit; II = uncleaved polypeptides; III = the three largest $\mathrm{CNBr}$ fragments; $\mathrm{IV}=$ the small $\mathrm{CNBr}$ fragments.

latter two peaks contain the fragments having most of the cysteines.

Dansylation yielded the following $\mathrm{N}$-terminal amino acids: alanine and proline from peak II, serine or none from peak III, histidine and arginine from peak IV, isoleucine or isoleucine and threonine from peak $\mathrm{V}$, proline and lysine from peak VI. Thus $9 \mathrm{CNBr}$-cleavage points could be accounted for, if the two prolines derive from different fragments and the »none from an $\mathrm{N}$-terminally blocked fragment.

\subsection{Ion-exchange chromatography of $\mathrm{CNBr}$ - fragments of S-4-pyridylethylated large subunit, followed by gel filtration}

Chromatography on carboxymethyl-cellulose separated the $\mathrm{CNBr}$-fragments into 9 polypeptide containing peaks, designated 1 to 9 (Figure 4). The peptides of these peaks were purified by gel filtration as presented in Figure 5.

Amino acid analysis, dansylation analysis and two dimensional TLC of tryptic digests revealed peaks 1,4 and 5 to contain the same fragment having $\mathrm{N}$-terminal proline and lacking homoserine and its lactone. In one experiment an extra fragment $(5 \mathrm{X})$ with a lower molecular weight was purified from peak 5 . It had also $\mathrm{N}$-terminal proline, contained homoserine and its lactone and was later found to have the same $\mathrm{N}$-terminal sequence (29) as the larger fragment of peak 5 . The large fragment with $\mathrm{N}$-terminal proline is therefore believed to be at the C-terminus of the large subunit and the fragment $5 \mathrm{X}$ is considered to be its $\mathrm{N}$-terminal part resulting from additional CNBr-cleavage. By SDS-polyacrylamide gel 


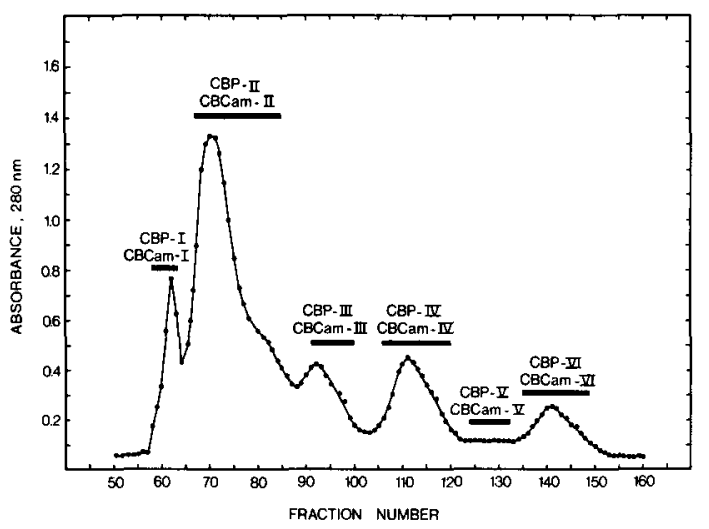

Figure 2. Elution profile after gel filtration of $20 \mathrm{mg}$ of cyanogen bromide fragments of S-carboxymethylated (CBCam-) large subunit from barley ribulose bisphosphate carboxylase on Bio-Gel P-30 (cf. 2.5). 2 $\mathrm{ml}$ fractions were collected. Polypeptide containing

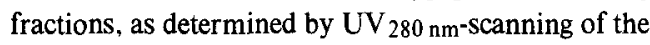
column eluates, were dried in an evacuated desiccator over solid $\mathrm{NaOH}$. After drying, the samples were redissolved in $0.1 \mathrm{M}-\mathrm{NH}_{4} \mathrm{OH}$ and measured in the spectrophotometer. Samples were then pooled, as indicated with the bars and freeze dried. Cyanogen bromide fragments of S-4 pyridylethylated (CBP-) large subunit were separated with a very similar elution profile.

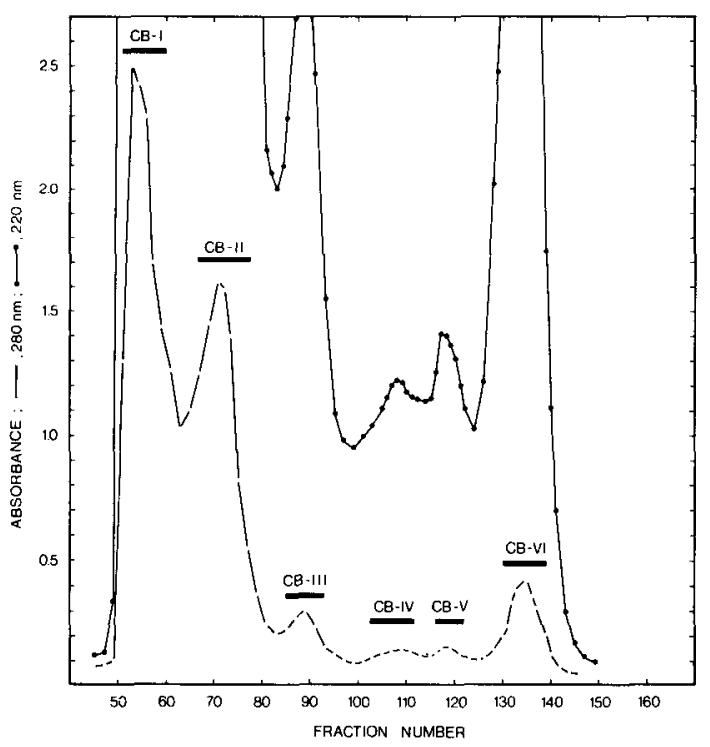

Figure 3. Elution profile after gel filtration of $50 \mathrm{mg}$ of cyanogen bromide fragments of unmodified large subunit from barley ribulose bisphosphate carboxylase on Bio-Gel P-30 (cf. 2.5). electrophoresis (Figure 7, track 8) these two fragments were identified as the two lower prominent bands in area III of Figure 1.

Gel filtration separated peak 2 into two fragments of different size, one having $\mathrm{N}$ terminal alanine and the other serine (CM2-I and CM2-II). The fragment with $\mathrm{N}$-terminal alanine was found to be the band with the largest apparent molecular weight in area III of Figure 1 as evidenced by track 9 in Figure 7 .

Peak 3 contained the smallest fragment. It had $\mathrm{N}$-terminal proline and its high absorption at $280 \mathrm{~nm}$ could be attributed solely to tryptophan by amino acid analysis.

Peaks 6 and 7 contained the same fragment as judged by amino acid composition and tryptic peptide maps. The fragment is blocked to the dansylation procedure and $\mathrm{N}$-terminal sequencing (29). Peak 8 contained a fragment with $\mathrm{N}$ terminal isoleucine, whereas insufficient material was obtained from peak 9 for analytical purposes. Six of the possible ten fragments were thus recovered by ion-exchange chromatography and gel filtration. One of the fragments apparently contains an internal methionine not easily accessible to $\mathrm{CNBr}$-cleavage and was shown to account for two fragments.

\subsection{Gel filtration of CNBr-fragments of S- carboxymethylated large subunit followed by ion-exchange chromatography}

Realising that the four fragments not retrieved by CM-cellulose chromatography of the S-4pyridylethylated fragments were obtainable by gel filtration, it was decided to use gel filtration as the first step in the purification. The four fragments looked for, had N-terminal histidine, arginine, threonine and lysine respectively and had been found to elute in peaks IV, V and VI (cf. 3.2) from the Bio-Gel column. Since the fragments in peak IV could contain cysteines and since their S-4-pyridylethylation could be the reason for the loss of these fragments during ion exchange chromatography, the large subunit was S-carboxymethylated, so that acidic rather than basic groups were introduced. From this preparation $4 \times 35 \mathrm{mg} \mathrm{CNBr}$ fragments were subjected to gel filtration and the material in peaks II to VI (cf. Figure 2) collected. Purifica- 
C. POULSEN: Cyanogen bromide fragments of ribulosebisphosphate carboxylase

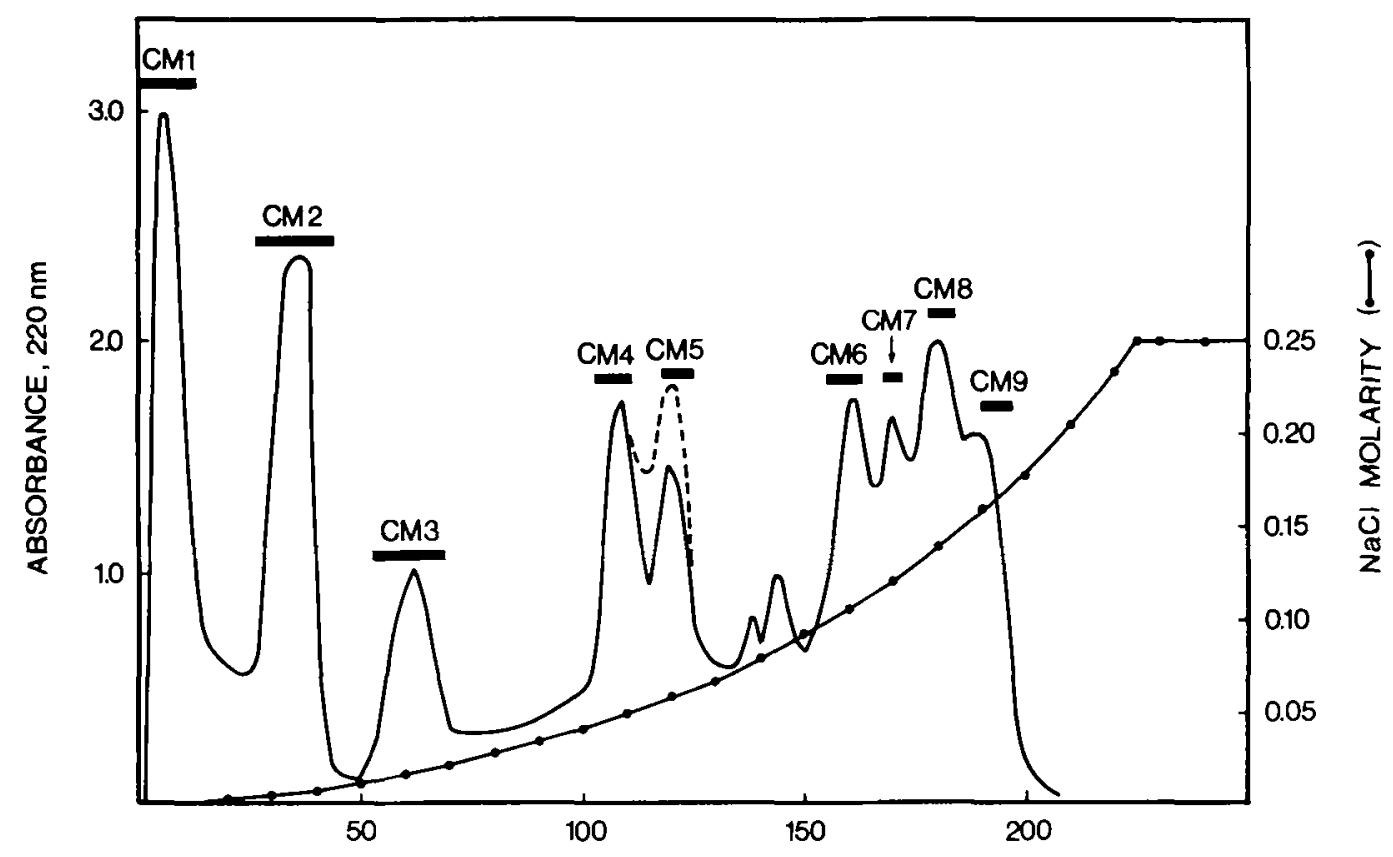

ELUTION VOLUME, MILLILITERS

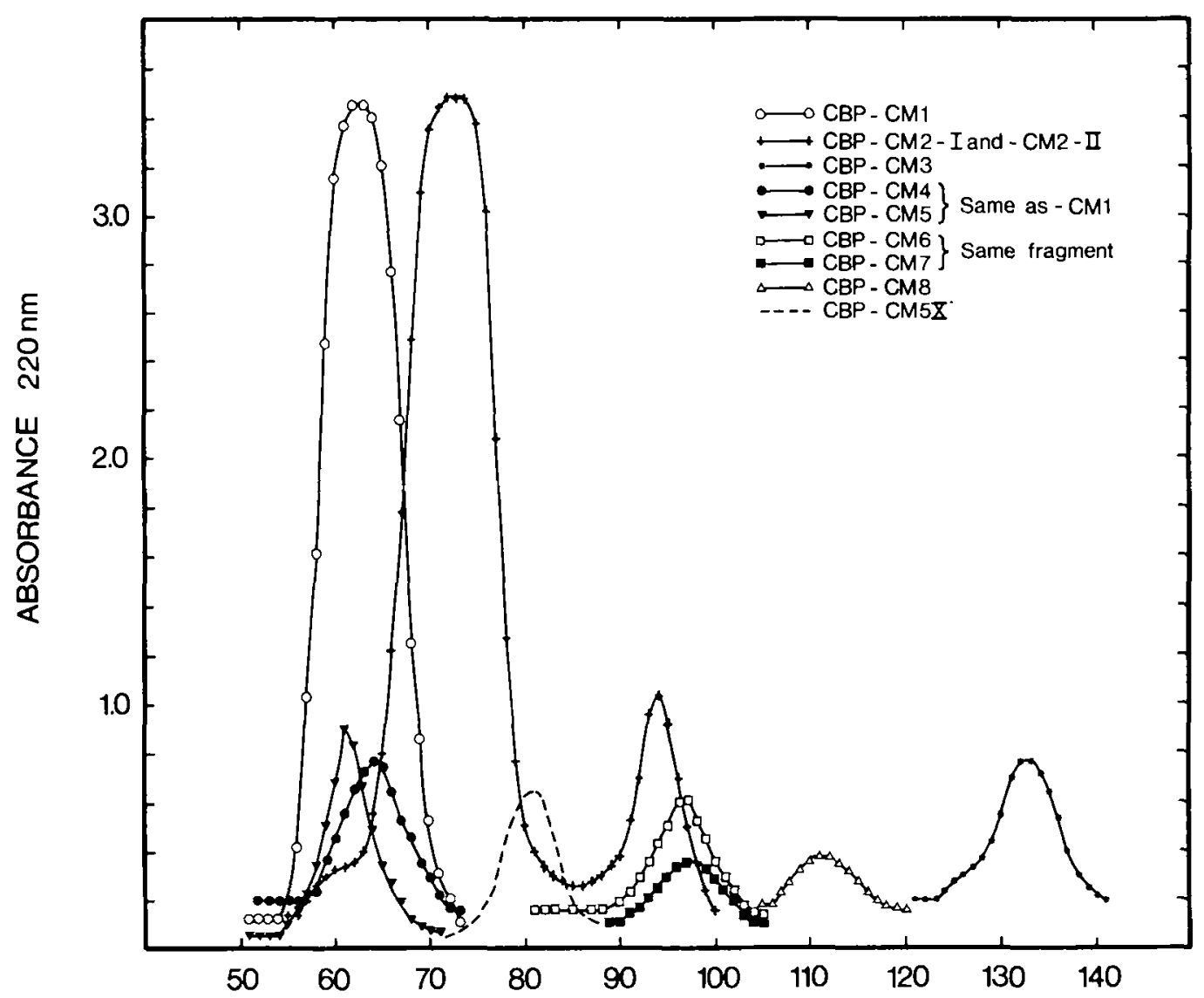


Figure 4. Ion exchange chromatography of $35 \mathrm{mg}$ cyanogen bromide fragments from S-4-pyridylethylated large subunit of barley ribulose bisphosphate carboxylase. The fragments were dissolved in $25 \mathrm{~mm}$-ammonium acetate pH 5.0, $8 \mathrm{M}$ in urea, and applied to a $0.9 \times 10 \mathrm{~cm}$ column of CM-cellulose equilibrated in the same buffer. The column was developed with $250 \mathrm{ml}$ of the buffer, containing an exponential gradient of $0-0.25 \mathrm{M}-\mathrm{NaCl} .1 \mathrm{ml}$ fractions were collected and measured in the spectrophotometer at $220 \mathrm{~nm}$. Fractions were pooled as indicated with the bars, and desalted on a $2.5 \times 35 \mathrm{~cm}$ column of Sephadex G-25 Superfine in $0.1 \mathrm{M}-\mathrm{NH}_{4} \mathrm{OH}$. CBP-CM fragments were freeze dried and further purified by gel filtration, as shown in Figure 5. The broken line refers to position of an extra fragment, CBP-CM $5 \mathrm{X}$, obtained in a second experiment, where $155 \mathrm{mg}$ of fragments $(2.8$ $\mu$ moles) were applied to a $1.6 \times 12 \mathrm{~cm}$ column and $3 \mathrm{ml}$ fractions were collected, during development of the column with a 1 litre gradient.

Figure 5. Purification of the cyanogen bromide fragments of S-4-pyridylethylated large subunit obtained by ion exchange chromatography (Figure 4) on a column of Bio-Gel P-30 (cf. 2.5).

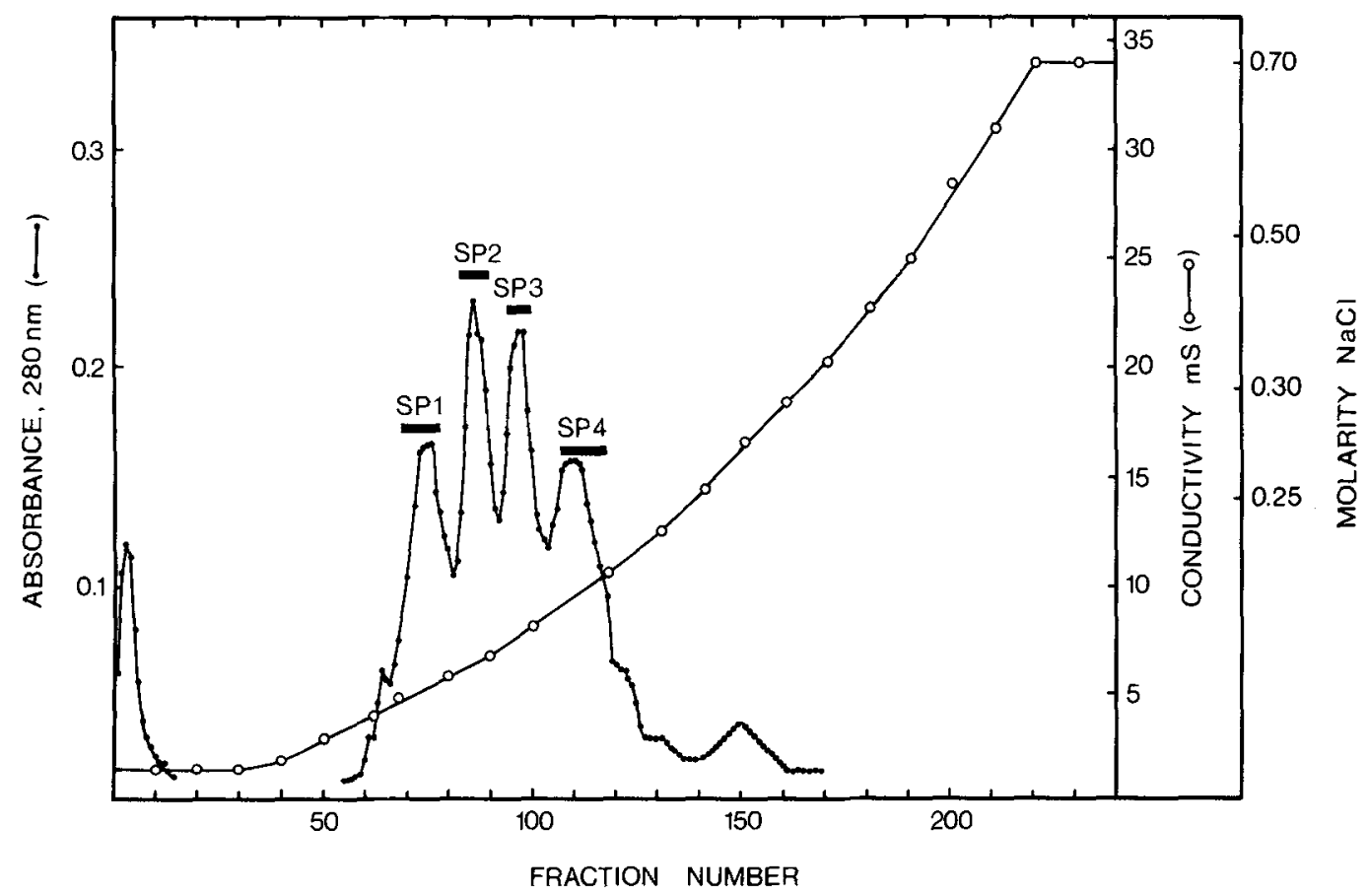

Figure 6. Ion-exchange chromatography of one third of the total pool of CBCam-II fragments, which were isolated by gel filtration as shown in Figure 2. The column was a $0.9 \times 9 \mathrm{~cm}$ SP-Sephadex C-25 equilibrated with $40 \mathrm{~mm}$-ammonium formiate at $\mathrm{pH} 3.60,8 \mathrm{~m}$ in urea. The polypeptide fragments were eluted with a 1 litre exponential gradient of $0-0.7 \mathrm{M}-\mathrm{NaCl}$ in the same buffer. $4 \mathrm{ml}$ fractions were collected and measured at $280 \mathrm{~nm}$. Appropriate fractions were pooled as indicated with the bars.

tion of the material in the peaks was done by ionexchange chromatography.

Peak II peptides were thus separated into 4 fractions on the stronger cation-exchanger SPSephadex in ammonium formiate $\mathrm{pH} 3.6,8 \mathrm{M}$ in urea (Figure 6). After three chromatographies of this type, the material of the four fractions was rechromatographed on the Bio-Gel P-30 column and compared by SDS-polyacrylamide gel electrophoresis with the peptides obtained using ion exchange chromatography prior to gel filtration (Figure 7). The SP-Sephadex fractions 1 and 2 


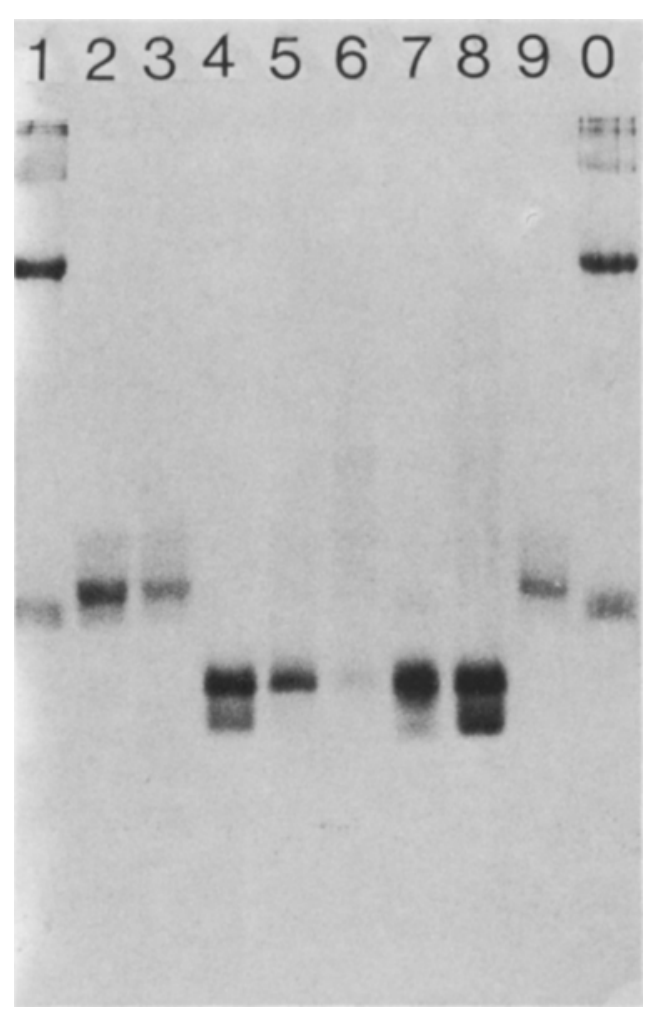

Figure 7. SDS polyacrylamide gel electrophoresis (2.6) of $\mathrm{CNBr}$-fragments from the large subunit of ribulose bisphosphate carboxylase from barley. The following samples were run: Track 1 and $10,30 \mu \mathrm{g}$ of barley ribulose bisphosphate carboxylase large and small subunit; track 2, 1 nmole of CBCam-IISP1; track 3, 0.7 nmoles of CBCam-IISP2; track 4, 2 nmoles of CBCam-IISP3; track 5, 1 nmoles of CBCam-IISP4; track 6,1/20 of the CBCam-I pool; track 7, 2 nmoles of CBC-CM 1; track 8, 2.5 nmoles of CBP-CM5; track 9, 0.7 nmoles of CBP-CM2-I.

contained the $\mathrm{CNBr}$ fragment with $\mathrm{N}$-terminal alanine previously identified in the CM2-I fraction (Figure 7, tracks 2, 3 and 9). The SPSephadex fraction 3 contained two peptides (Figure 7, track 4) the larger corresponding to the $\mathrm{CNBr}$ fragment with $\mathrm{N}$-terminal proline (CM1, Figure 7, track 7), and was obtained in pure form in the SP-Sephadex fraction 4 (Figure 7 , track 5). Fraction 3 had only $\mathrm{N}$-terminal proline and one third to one half equivalent of homoserine and its lactone. As the electrophore-

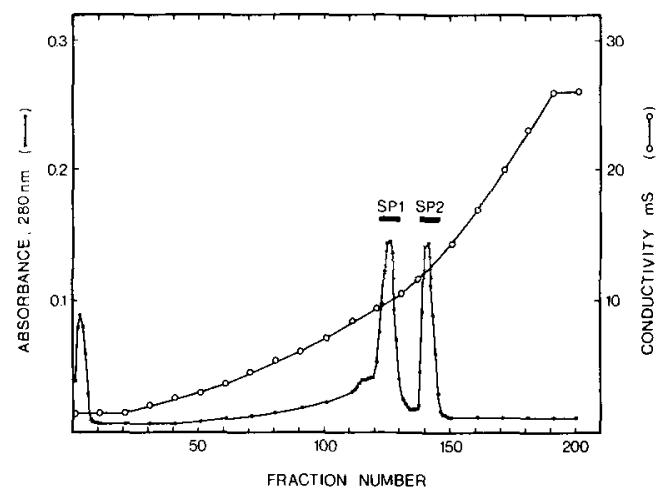

Figure 8. Ion-exchange chromatography of CBCamIII fragments which had been isolated by gel filtration (cf. Figure 2). The column was a $0.9 \times 6 \mathrm{~cm} \mathrm{SP}$. Sephadex C-25, equilibrated with 50-mm-ammonium formiate at $\mathrm{pH} 3.60,8 \mathrm{~m}$ in urea. The column was developed with a $700 \mathrm{ml}$ exponential gradient of 0$0.5 \mathrm{M}-\mathrm{NaCl}$ in the same buffer. $3.5 \mathrm{ml}$ fractions were collected and monitored at $280 \mathrm{~nm}$. Fractions were pooled as shown with the bars.

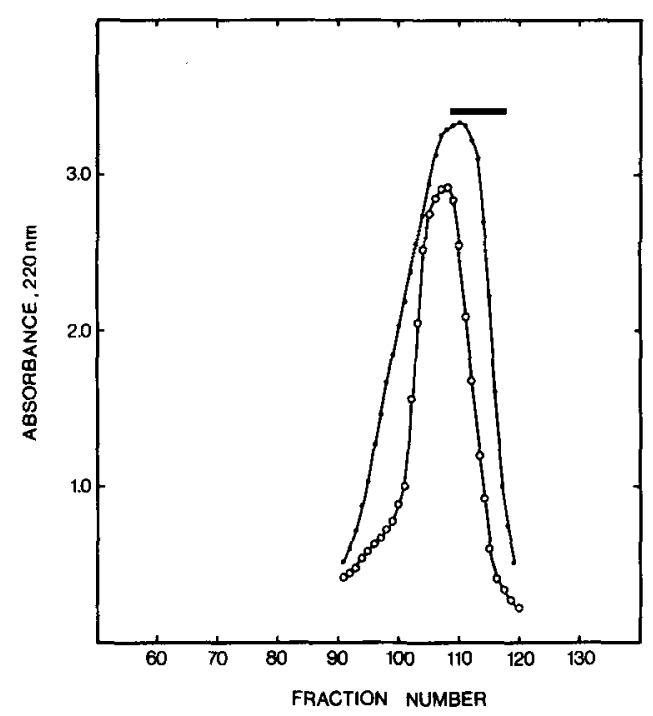

Figure 9. Purification by gel filtration of cyanogen bromide fragments contained in the CBCam-IV peaks from experiments corresponding to that of Figure 2 (cf. 2.5). The dotted curve was the elution profile of the first filtration. Fractions corresponding to the bar were pooled and further chromatographed as shown with the circles. 


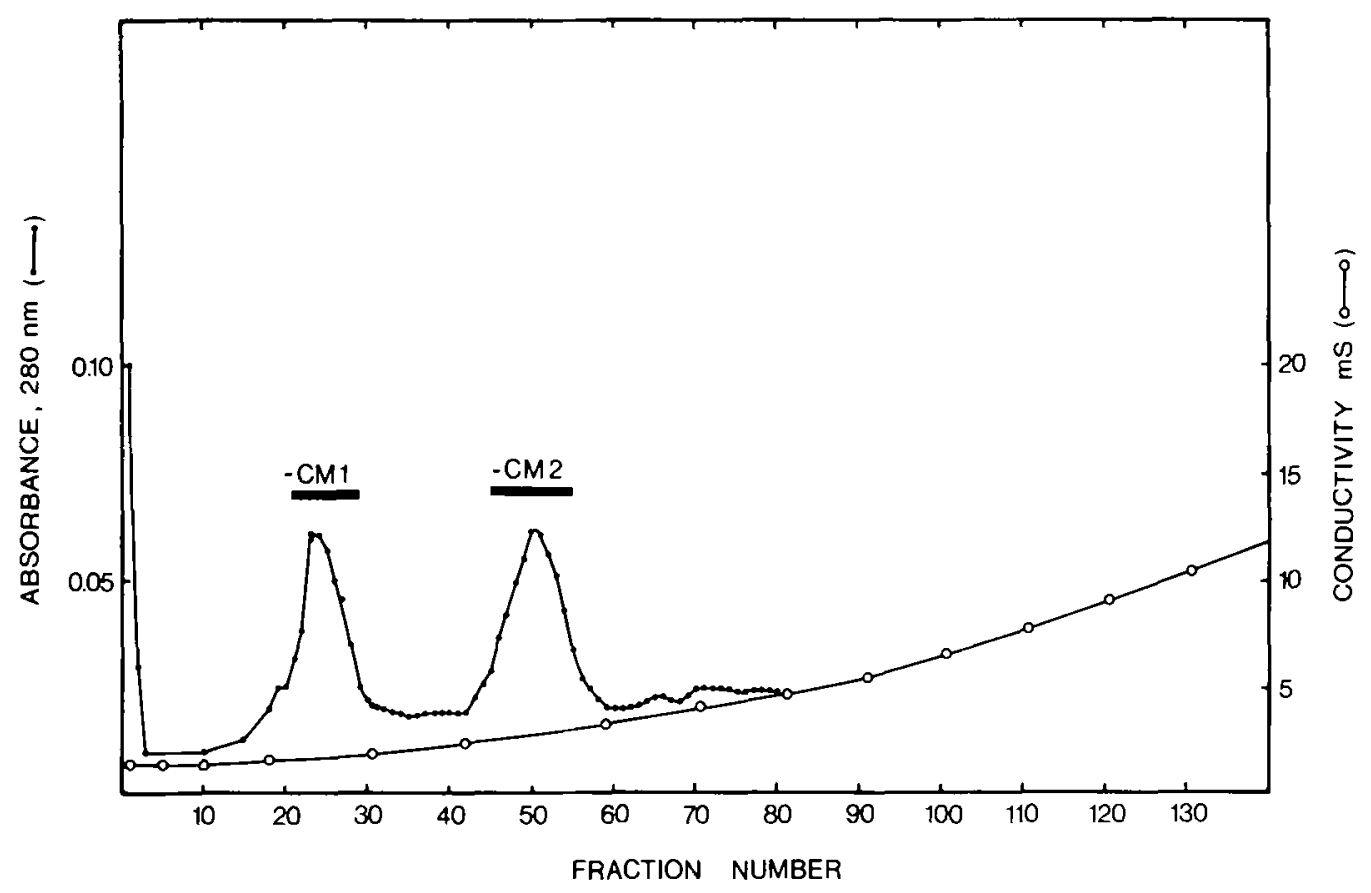

Figure 10. Ion exchange chromatography of CBCam-IV fragments purified in the experiment of Figure 9. Polypeptide material containing 1.5 umoles of homoserine and homoserine lactone was dissolved in $2 \mathrm{ml}$ of 20 mM-ammonium acetate, $8 \mathrm{M}$ in urea, and applied to a $0.9 \times 8 \mathrm{~cm}$ column of CM-cellulose equilibrated in the same buffer. The column was developed with a $600 \mathrm{ml}$ exponential gradient of $0-0.25 \mathrm{M}-\mathrm{NaCl}$ and $3.5 \mathrm{ml}$ fractions were collected.

tic pattern (Figure 7, track 4) was identical to that of the CM5 fraction (Figure 7, track 8) the smaller fragment in the mixture is identified as the $\mathrm{N}$-terminal portion of the proline fragment at the $\mathrm{C}$-terminus. This portion results from complete $\mathrm{CNBr}$ cleavage as previously deduced (3.3).

Peak III peptides were separated into two fractions by chromatography on SP-Sephadex (Figure 8). As judged by amino acid composition, the first of the two peaks (CBCam-IIISP1) contained the $\mathrm{N}$-terminally blocked fragment previously identified as CM6 and CM7, and the second peak (CBCam-IIISP2) was the N-terminal serine fragment previously known as CM2II.

The peak IV peptides containing two of the four $\mathrm{CNBr}$ fragments not retrieved by $\mathrm{CM}$ cellulose chromatography were twice rechromatographed on the Bio-Gel P-30 column (Figure 9). Dansyl-analysis and the shape of the elution profile indicated the mixture of the fragments with N-terminal histidine and arginine to be pure. The total yield of homoserine and its lactone in the amino acid analysis was 3.0 $\mu$ moles corresponding to a yield of $60 \%$. Ionexchange chromatography on SP-Sephadex C-25 yielded two equally sized peaks as did the other half of the sample subjected to CM-cellulose chromatography (Figure 10). Both peaks contained the mixture of the two fragments. An experiment to separate the mixture on a DEAEcellulose column was likewise unsuccessful. The purified mixture could however be used to establish the $\mathrm{N}$-terminal sequences of both the arginine- and the histidine-fragments (29).

The peak $V$ peptides known to contain the fragment with $\mathrm{N}$-terminal isoleucine and the sought threonine fragment yielded little material after three purification steps on Bio-Gel P-30 (Figure 11). Dansyl analysis established that only fragments having $\mathrm{N}$-terminal isoleucine and 


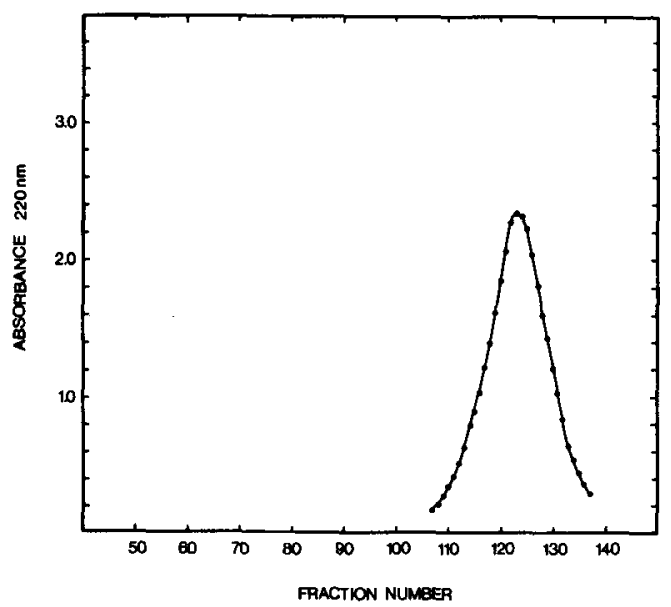

Figure 11. Purification by gel filtration of cyanogen bromide fragments in the $\mathrm{CBCam}-\mathrm{V}$ peaks from experiments corresponding to those of Figure 2 (cf. 2.5). The shown peak was obtained after three rechromatographies. At each chromatographic step $40 \%$ of the A $220 \mathrm{~nm}$-units were lost giving a total yield of about $13 \%$ of the starting material after four steps.

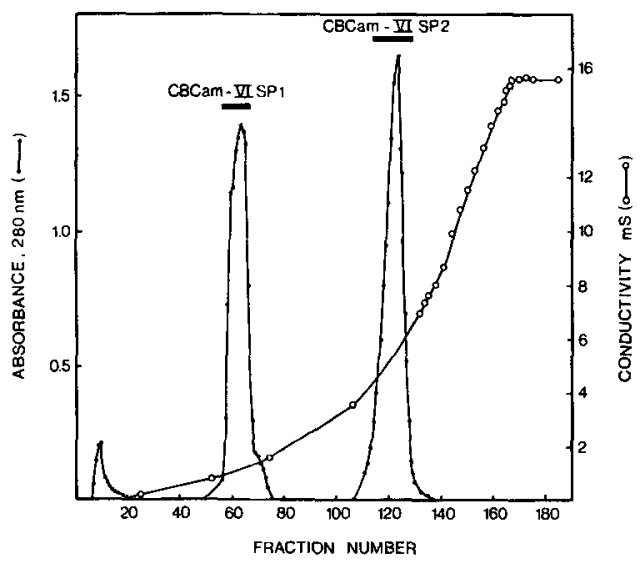

Figure 12. Ion exchange chromatography of CBCamVI fragments obtained as shown in Figure 2 and purified by gel filtration (cf. 2.5). The column was a $0.9 \times 12 \mathrm{~cm}$ SP-Sephadex C-25 equilibrated with 0.05 M-pyridine acetate $\mathrm{pH} 2.45$ (30\% acetic acid by volume) at $50^{\circ} \mathrm{C}$. The sample, containing peptide material with aitogether $2 \mu$ moles of homoserine and homoserine lactone was applied in $4 \mathrm{ml}$ of the buffer. The peptides were eluted over 24 hours with $750 \mathrm{ml}$ of an exponential gradient of $0-0.25 \mathrm{M}-\mathrm{NaCl} .4 \mathrm{ml}$ fractions were collected and monitored at $280 \mathrm{~nm}$. After drying, the fractions were redissolved in $1 \mathrm{ml}$ of $0.1 \mathrm{~m}-\mathrm{NH}_{4} \mathrm{OH}$ and measured at $225 \mathrm{~nm}$ but no additional material was uncovered. threonine were present. Attempts to separate the two fragments by SP-Sephadex and CM-cellulose chromatography were unsuccessful.

The peak VI peptides contained two fragments, one with $\mathrm{N}$-terminal lysine and the other with N-terminal proline. The former was lost in the CM-cellulose chromatography procedure and could not be purified on SP-Sephadex and DEAE-cellulose. Figure 12 presents an experiment using SP-Sephadex which resulted in two peaks both containing the proline-fragment in pure form. Peptide mapping and amino acid sequencing of the purified proline fragment and the peak VI mixture has been carried out, which permits to characterise the lysine fragment by inference.

\subsection{Characterization of the Ala-fragment of 15,000 dalton}

Table II gives the amino acid composition based on the apparent molecular weight of 15,000 dalton as determined by SDS-polyacrylamide gel electrophoresis and the presence of 1 equivalent of homoserine plus its lactone. The fragment contains 134-137 amino acids. The composition of the fragment isolated in two different ways agrees well. The most striking features of the fragment are the high content of threonine and tyrosine, and the low content of basic amino acids. Furthermore, this fragment is found to contain at least two cysteines. It should be noted that S-pyridylethyl-cysteine (PECys) co-elutes with lysine on the amino acid analyzer. However, the content of lysine plus PE-cysteine in CBP-CM2-I is comparable to the content of lysine and S-carboxymethylcysteine in CBCamIISP1 and -SP2.

With five lysines and four arginines one would expect 10 peptides in case of ideal tryptic cleavage. Figure 13 shows a tryptic peptide map of this fragment, in which 13 flourescamine positive peptides were found. Eight of these (A-I) yielded an amino acid composition of good stoichiometry accounting at best for close to half of the fragment (Table III). Unfortunately cysteine and homoserine were not present in any of these tryptic peptides. The spots $1-6$ contained non-stoichiometric amino acid mixtures and are considered to contain incompletely digested 


\section{Table II}

Amino acid composition of the Ala-fragment of 15,000 dalton isolated in two different ways.

\begin{tabular}{lcc}
\hline Amino acid & CBP-CM2-I & $\begin{array}{c}\text { CBCam-IISP1 } \\
\text { CBCam-IISP2 }\end{array}$ \\
\hline CMCys & - & 2.3 \\
Asx & 11.2 & 11.2 \\
Thr & 12.5 & 12.4 \\
Ser & 5.5 & 5.3 \\
Glx & 17.0 & 16.9 \\
Pro & 9.8 & 10.0 \\
Gly & 11.2 & 11.4 \\
Ala & 14.1 & 14.3 \\
Val & 10.6 & 10.9 \\
Ile & 4.0 & 4.0 \\
Leu & 8.9 & 8.8 \\
Tyr & 9.8 & 9.9 \\
Phe & 2.7 & 2.8 \\
His & 1.2 & 1.2 \\
Lys & & 4.8 \\
Lys + PECys & 7.0 & \\
Arg & 3.7 & 3.8 \\
Homoserine & & \\
+ lactone & 1.0 & 1.0 \\
Yield & $18 \%$ a) & $10 \%$ b) \\
\hline
\end{tabular}

a) 450 nmoles were isolated from $2.8 \mu$ moles of large subunit.

b) $240 \mathrm{nmoles}$ were isolated from $2.5 \mu$ moles of large subunit.

\section{Table III}

Amino acid composition and $\mathrm{N}$-terminal amino acid residues, for the tryptic peptides of the Ala-fragment of 15,000 dalton (CBP-CM2-I and CBCam-IISP $1+2$ ). The peptides were obtained from 5 plates with the pattern shown in Figure 13.

\begin{tabular}{|c|c|}
\hline Peptide & \\
\hline A & 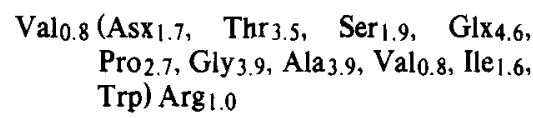 \\
\hline B & Gly $_{0.9}-\operatorname{Arg}_{1.0}$ \\
\hline $\mathrm{D}$ & 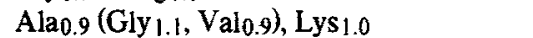 \\
\hline $\mathrm{E}$ & Tyr $0.9\left(\right.$ Val $\left._{0.8}\right)$ Lys $_{1.0}$ \\
\hline $\mathrm{F}$ & His \\
\hline $\mathrm{G}$ & Tyro.6 (Gly 1.2, Lys 1.0, Arg 1.0) \\
\hline $\mathrm{H}$ & $\begin{array}{c}\text { Leu }_{1.0}\left(\operatorname{Thr}_{2.6}, \text { Glx }_{2.1}, \quad \text { Prol.0, }\right. \\
\text { Lys }_{1.0}\end{array}$ \\
\hline I & $\begin{array}{rrrr}\operatorname{Asx}_{0.7}\left(\text { Asx }_{1.0},\right. & \text { Thr }_{0.8}, & \text { Ala } 1.8, & \left.\text { Phe }_{0.9}\right) \\
\operatorname{Arg}_{1.0} & \end{array}$ \\
\hline
\end{tabular}

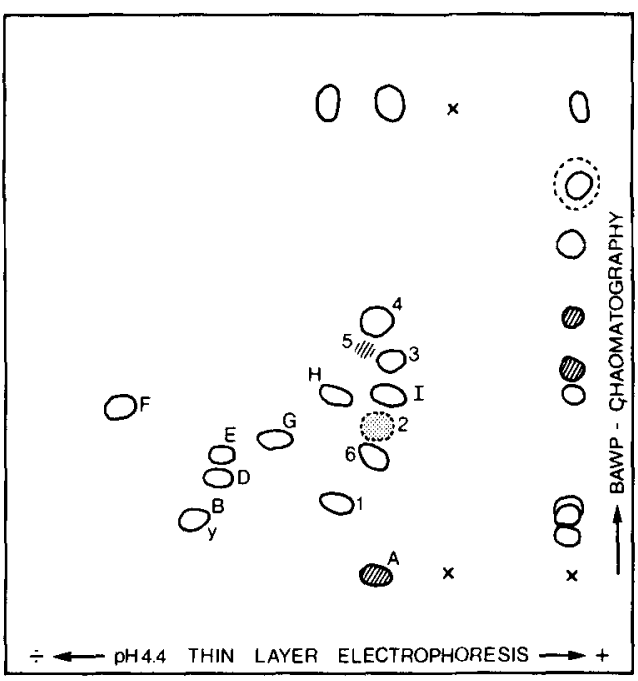

Figure 13. Tryptic fingerprint of fragments CBP. CM2-I on cellulose thin layer which is also representative for the fingerprint of CBCamIISP1 +2 . The diagram is a composite of 3 chromatograms. One of the plates was stained with the cadmium ninhydrin reagent, followed by Ehrlichs reagent for tryptophan (cross-hatched). The remaining two plates were stained with the fluorescamine reagent. Peptide B stained yellow (y) with cadmium ninhydrin. All other cadmium ninhydrin positive peptides were red. Peptide 5 was fluorescamine and ninhydrin negative, but stained for tryptophan. BAWP = butanol: acetic acid: water: pyridine. The reference amino acids at right are from bottom to top: Arg, Lys, Gly, His, Trp, Trp, DNP-Asp + Tyr, $\varepsilon$ DNP-Lys + Dansyl-Arg. The reference compounds at the top of the plate are from right to left: DNPAsp, $\varepsilon$-DNP-Lys, Dansyl-Arg.

peptide material and the missing peptides. Regarding the tryptophan content of this fragment, three peptide spots stained for tryptophan. One of these (A) seemed to be an ideal tryptic peptide, whereas the two others may have been incompletely digested peptides containing the same tryptophan. Accordingly there may be two or three tryptophans in the Ala-fragment. The origin of peptide spot $\mathrm{F}$, being a free histidine residue cannot be accounted for. 
Table IV

Amino acid composition of Pro-fragment of 10,000 dalton isolated in two different ways.

\begin{tabular}{lcc}
\hline Amino acid & CBP-CMla) & CBCam-IISP4a) \\
\hline CMCys & - & 1.9 \\
Asx & 8.0 & 8.0 \\
Thr & 3.9 & 4.6 \\
Ser & 1.8 & 2.6 \\
Glx & 11.0 & 11.0 \\
Pro & 4.8 & 5.0 \\
Gly & 9.1 & 9.1 \\
Ala & 13.1 & 12.7 \\
Val & 5.8 & 5.9 \\
Ile & 3.9 & 3.8 \\
Leu & 6.0 & 6.0 \\
Tyr & 3.1 & 2.6 \\
Phe & 3.1 & 3.1 \\
His & 1.0 & 0.9 \\
Lys & - & 4.0 \\
Lys + PECys & 5.7 & \\
Arg & 3.9 & 4.2 \\
Homoserine & & \\
+ lactone & 0.1 & 0.2 \\
Yield & $24 \% \mathrm{~b})$ & $21 \% \mathrm{c})$ \\
\hline
\end{tabular}

a) Values are based on a best fit for a 10.000 molecular weight peptide having 6.0 leucines and 8.0 aspartic acids.

b) 670 nmoles were finally purified from $2.8 \mu$ moles of large subunit.

c) 530 nmoles were obtained from 2.5 pmoles of large subunit.

\subsection{Characterization of Pro-fragment of 10,000 daltons}

Table IV gives the amino acid composition of the purified Pro-fragment, which had not undergone the internal $\mathrm{CNBr}$-cleavage at one internal methionine as described in 3.3 and 3.4. The fragment contains $90-92$ amino acids. The internal methionine was not detectable in the amino acid analysis.

Some material was used for tryptic peptide mapping. After ideal tryptic cleavage, one would expect 9 peptides (four lysines and four arginines). The tryptic peptide maps of the two preparations, being either S-4-pyridylethylated or S-carboxymethylated, were clearly different on the basis of fluorescamine positive spots
Table V

Amino acid composition and $\mathrm{N}$-terminal amino acid residues for the tryptic peptides of the Pro-fragment of 10,000 dalton (CBP-CM1 and CBCam-IISP4). The peptides were obtained from 5 plates with the patterns shown in Figure 14.

\begin{tabular}{|c|c|}
\hline \multicolumn{2}{|c|}{ Peptide } \\
\hline J & $\begin{array}{c}\text { Asx }_{0.9}\left(\text { Glx }_{0.9}, \text { Gly }_{0.7}, \text { Ala } 0.8, \text { Ile } 0.6, \text { Leu }_{0.7},\right. \\
\text { Trp) Arg } 1.0\end{array}$ \\
\hline $\mathbf{K}$ & $\operatorname{Asx}_{0.9}\left(\operatorname{Gly}_{1.2}\right.$, Glx $\left._{0.9}\right), \operatorname{Arg} 1.0$ \\
\hline $\mathrm{L}$ & $\left(\mathrm{Val}_{0.8}\right.$. Lys $\left._{1.0}\right)$ \\
\hline $\mathbf{M}$ & Ala $_{1.1}\left(\mathrm{Gl}_{0.5}, \mathrm{Ile}_{1.0}\right) \mathrm{Lys}_{1.0}$ \\
\hline $\mathrm{N}$ & 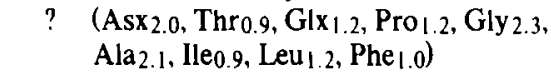 \\
\hline 0 & $\operatorname{Ala}_{0.8}\left(\right.$ Ala $_{1,0}$, Lys $\left._{1.0}\right)$ \\
\hline
\end{tabular}

present (Figure 14). The peptides marked with stars were present only on one or the other of the two sets of maps and gave too low yields for useful amino acid analysis. The same applied to unmarked peptide spots, which were similar in the two sets of maps. The peptide spots 7 and 8 gave very high yields of apparently incompletely digested material and peptide 8 contained methionine not modified by $\mathrm{CNBr}$. Peptide spots 7 and 8 contained cysteine, whereas no cysteine was found in the analyzed peptides $\mathrm{J}-\mathrm{O}$. The latter 6 peptides stained intensely with the cadmium ninhydrin reagent and yielded fairly good amino acid compositions after elution (Table V).

None of the peptides contained homoserine or its lactone. Peptide $\mathrm{N}$ lacked lysine and arginine and peptide $\mathrm{L}$ had its lysine as $\mathrm{N}$-terminus rather than as C-terminus. Both of these peptides could have originated by unspecific tryptic cleavage, or represent the $\mathrm{C}$-terminus of the intact large subunit. Of the missing peptides, one is probably from the $\mathrm{N}$-terminus of the fragment, having a more than 30 residue sequence without lysine and arginine (29). Other missing peptides are probably partially contained in peptide spots 7 and 8.

At least one tryptophan is contained in peptide $\mathrm{J}$, and with one tryptophan in the 53 residue sequence at least two tryptophans are accounted for in this fragment. 


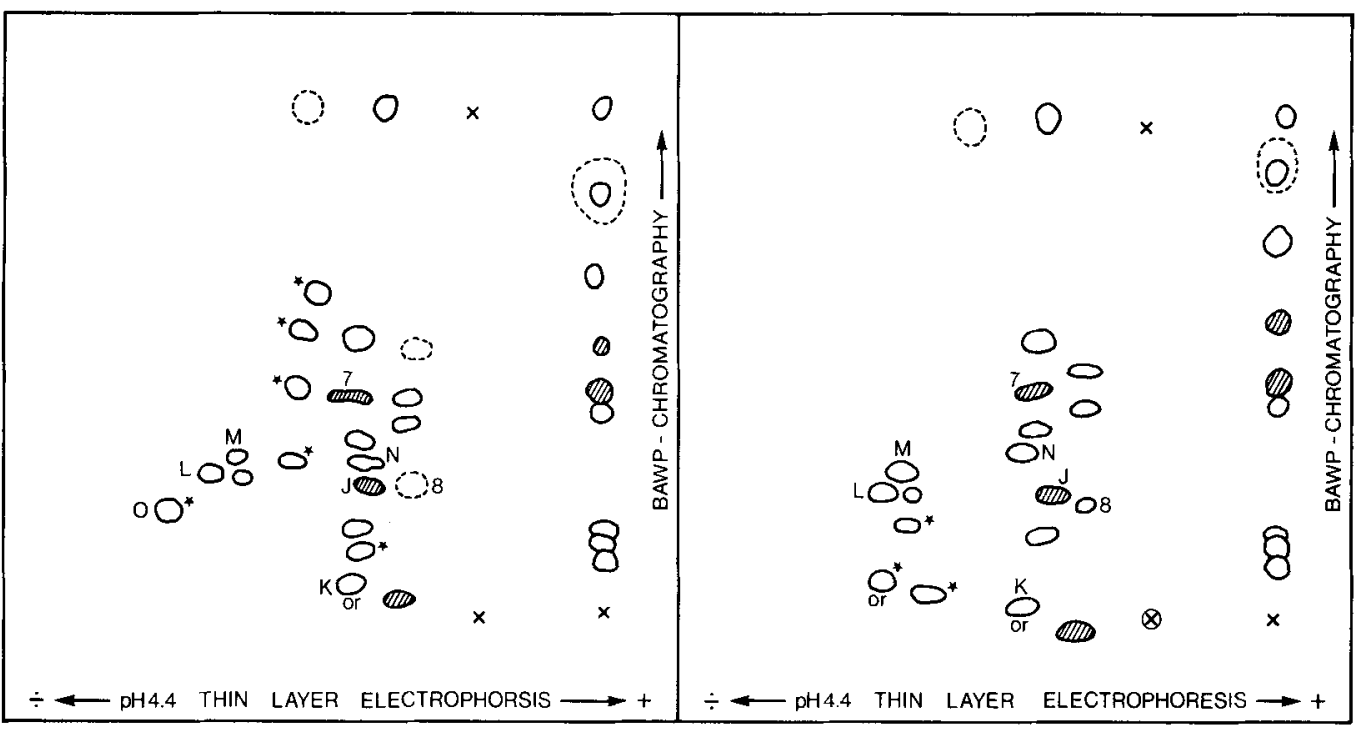

Figure 14. Tryptic fingerprints of fragments CBP-CM 1 (left) and CBCam-IISP4 (right) on cellulose thin layers. After electrophoresis and chromatography, one of the $2 \times 3$ plates was stained with the cadmium ninhydrin reagent, followed by Ehrlichs reagent for tryptophan (cross-hatched). The remaining five plates were stained with the fluorescamine reagent. Orange cadmium ninhydrin-spots are designated or. Differences between the maps are indicated with stars.

\subsection{Characterization of the fragments with $\mathbf{N}-$ terminal serine and with the $\mathrm{N}$-terminally blocked group}

Table VI shows the amino acid composition of the N-terminally blocked fragment with 65 amino acids. The CB-III fragment isolated in the experiment shown in Figure 3 turned out to be pure. As shown by attempted N-terminal sequencing and by the dansylation procedure no free $\mathrm{N}$-terminal amino acid was present. The amino acid composition is not significantly different from that of the fragment isolated by ion-exchange chromatographies (CBP-CM6 and -CM7 and CBCam-IIISP1). Furthermore, the fragment thus isolated in three different ways did not show differences in the tryptic peptide mapping (Figure 15 B) and was found, on basis of the specific stains, not to be contaminated with the serine-fragment (Figure $15 \mathrm{~A}$ ), which was of similar size. The number of 8 detected tryptic peptides is close to the 9 expected from the number of lysine and arginine residues. A peptide which stained with the $\mathrm{Cl}_{2} / \mathrm{starch} / \mathrm{KI}$ - reagent (17) and which did not stain with the ninhydrin reagent at the same time was not observed. Accordingly, the $\mathrm{N}$-terminally blocked tryptic peptide is assumed to stick to the origin of the thin layer. The peptide material at the origin was found to stain for tyrosine, histidine and arginine, but not for tryptophan. The peptide staining for tryptophan indicates the presence of at least one tryptophan in this fragment.

A 40 nmole sample was treated with the enzyme pyroglutamic acid aminopeptidase (27, 29) and with the dansylation prodedure. This resulted in a dominating spot of dansyl-valine with only faint traces of other derivatives on the thin layers. Accordingly, the N-terminus of this peptide is considered to be a cyclized glutamine followed by a valine in the second position.

Table VII shows the amino acid composition of the fragment with $\mathrm{N}$-terminal serine containing 52 residues. Two different ways of purification of this fragment did not result in any differences in the amino acid composition. The yields were quite low, but this was believed to be 
Table VI

Amino acid composition of the $\mathbf{N}$-terminally blocked fragment of 7,000 dalton isolated in three different ways.

\begin{tabular}{lccc}
\hline Amino acid & CB-III & $\begin{array}{c}\text { CBP-CM 6 } \\
\text { CBP-CM 7 }\end{array}$ & $\begin{array}{c}\text { CBCam- } \\
\text { IIISP1 }\end{array}$ \\
\hline CMCys & - & - & - \\
Asx & 5.0 & 4.9 & 5.0 \\
Thr & 4.5 & 4.3 & 4.9 \\
Ser & 1.6 & 1.3 & 1.7 \\
Glx & 8.5 & 9.0 & 8.8 \\
Pro & 1.0 & 0.9 & 0.7 \\
Gly & 7.0 & 6.2 & 6.8 \\
Ala & 7.9 & 8.2 & 8.5 \\
Val & 2.1 & 2.0 & 2.1 \\
Ile & 3.5 & 3.4 & 2.9 \\
Leu & 3.6 & 4.0 & 3.5 \\
Tyr & 3.0 & 2.8 & 3.2 \\
Phe & 3.0 & 2.8 & 3.2 \\
His & 1.8 & 2.2 & 2.7 \\
Lys & 4.5 & - & 4.0 \\
Lys + PECys & - & 4.2 & - \\
Arg & 3.6 & 4.4 & 3.9 \\
Homoserine & & & \\
+ lactone & 0.9 & 1.0 & 0.9 \\
& & & \\
Yield & n.d. & n.d. & $4 \%$ a) \\
\hline
\end{tabular}

a) Subjected to significant loss during desalting. The total yield was 100 nmoles of which 85 were used to find the nature of the $\mathrm{N}$-terminal blocking group, 15 nmoles were used for tryptic peptide mapping.

due to bad cleavage of Met-Ser peptide bonds. The main part of these batches were used for automatic sequencing (29).

The tryptic peptide map revealed eight peptides, which is in fair agreement with the seven expected from the number of lysines and arginines (Figures $15 \mathrm{~A}$ ). Four peptides stained for arginine and one for tryptophan, indicating at least one tryptophan in the sequence.

Only one peptide stained orange with cadmium ninhydrin. The same peptide was positive for the histidine stain (Pauly's reagent), having a bright cherry red colour. The material at the origin of the thin layer was positive too, but stained for tyrosine as well. This was not the case for the cadmium ninhydrin orange peptide. Since peptides having N-terminal serine stain

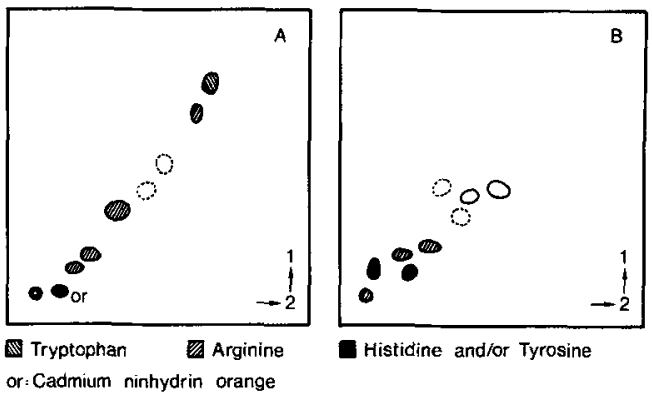

Figure 15. A: Tryptic peptide fingerprint of serine fragment CBP-CM2-II, which is also representative for the CBCam-IIISP2 fragment. B: Tryptic peptide fingerprint of the $\mathrm{N}$-terminally blocked fragment $\mathrm{CBP}-\mathrm{CM} 6+7$, which is also representative for CBCam-IIISP1 fragment. The two-dimensional chromatograms were run on $10 \times 10 \mathrm{~cm}$ silicagel thin layers and subsequently analyzed with the specific amino acid staining reagents (17), 1 and 2 are directions of chromatography (cf. 2.11) in the first (solvent A) and second (solvent B) dimensions, respectively.

\section{Table VII}

Amino acid composition of the Ser-fragment of 6,000 dalton isolated in two different ways.

\begin{tabular}{lcc}
\hline Amino acid & CBP-CM2-II & CBCam-IIISP2 \\
\hline CMCys & - & - \\
Asx & 6.0 & 6.0 \\
Thr & 2.7 & 2.9 \\
Ser & 1.8 & 2.1 \\
Glxa) & 6.1 & 4.0 \\
Pro & 0.2 & 0.3 \\
Gly & 7.1 & 7.1 \\
Alaa) & 2.2 & 2.6 \\
Val & 4.2 & 4.2 \\
Ile & 2.9 & 3.2 \\
Leu & 4.4 & 4.6 \\
Tyr & 0.8 & 0.9 \\
Phe & 3.6 & 3.9 \\
His & 1.7 & 2.0 \\
Lys & - & 2.1 \\
Lys + PECys & 2.1 & - \\
Arg & 3.6 & 4.1 \\
Homoserine & & \\
+lactone & 1.0 & 1.0 \\
Yieldb) & $4 \%$ & $6 \%$ \\
\hline
\end{tabular}

a) Differences in the values for Glx and Ala could not be accounted for by anything but the presence of impurities of other peptides.

b) The yield was 120 and 150 nmoles respectively in the two experiments. 
orange with cadmium ninhydrin (17), this peptide could be at the $\mathrm{N}$-terminus of the fragment, which is in agreement with the $\mathrm{N}$ terminal sequence (29) containing two histidine residues proximal to the first lysine at position 14.

\subsection{Characterization of the fragments with $\mathrm{N}$ - terminal histidine and arginine}

The CBCam-IV fragments obtained with Scarboxymethylated large subunits, were never obtained after CM-cellulose chromatography of the S-4-pyridylethylated fragments. The amino acid composition of the CBCam-IV mixture (Table VIII) shows that these fragments had a

\section{Table VIII}

Amino acid composition of the CBCam-IV fragments having $N$-terminal histidine $(4,500$ dalton $)$ and arginine $(4,500$ dalton).

\begin{tabular}{lccc}
\hline Amino acid & CBCam-IV & $\begin{array}{c}\text { CBCam- } \\
\text { IVCM1 }\end{array}$ & $\begin{array}{c}\text { CBCam- } \\
\text { IVCM2 }\end{array}$ \\
\hline CMCys & 2.8 & 2.6 & 2.4 \\
Asx & 7.2 & 7.0 & 7.0 \\
Thr & 6.0 & 5.6 & 6.2 \\
Ser & 1.4 & 1.0 & 1.0 \\
Glxa) & 9.8 & 5.8 & 7.8 \\
Pro & 1.0 & 1.0 & 0.8 \\
Gly & 8.6 & 6.8 & 7.2 \\
Alaa) & 11.0 & 7.8 & 9.2 \\
Val & 2.6 & 2.0 & 2.4 \\
Ile & 3.8 & 3.0 & 3.4 \\
Leu & 6.8 & 7.0 & 7.0 \\
Tyr & 4.0 & 3.8 & 4.6 \\
Phe & 3.8 & 3.6 & 4.2 \\
His & 4.2 & 4.6 & 4.0 \\
Lys & 3.0 & 2.4 & 2.6 \\
Arga) & 5.5 & 4.0 & 4.8 \\
Homoserine & & & \\
+ lactone & 1.8 & 1.8 & 2.0 \\
& & & \\
Yield & $60 \%$ & n.d.a) & n.d.a) \\
\hline
\end{tabular}

a) Yields cannot be calculated, as the three columns contain the compositions of a mixture of two fragments in slightly different ratios. This is most clear in the content of arginine, glutamate and alanine. The two peaks contained about 150 nmoles of homoserine(-lactone).

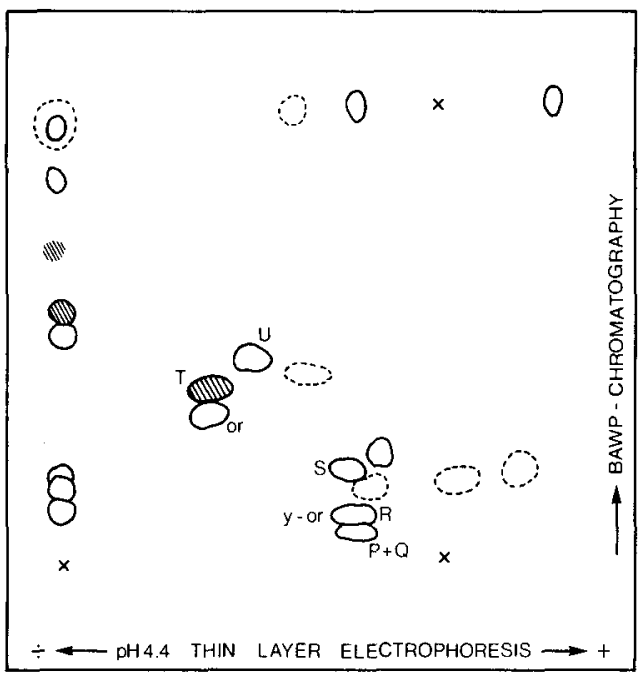

Figure 16. Tryptic fingerprint of fragments contained in the CBCam-IVCM1 peak of Figure 10. Six chromatograms were made, of which one was stained with the cadmium ninhydrin reagent, followed by the Ehrlichs reagent for tryptophan (cross-hatched). The remaining five plates were stained with the fluorescamine reagent. The peptide spots encircled with a broken line, showed up only on one of the fluorescamine stained plates. Yellow and orange cadmium ninhydrin positive spots are designated y and or.

high content of arginine, lysine and histidine in addition to three cysteines. S-4-pyridylethylated fragments have up to $15-16$ positively charged residues at $\mathrm{pH} 5.0$ out of a total of about 80 residues. This could be the reason for the very tight sticking of these fragments to CMcellulose, a property removed by S-carboxymethylation. Unfortunately, the two carboxymethylated fragments could not be separated on the cation exchangers as is obvious from the amino acid compositions of the two peaks eluted during CM-cellulose chromatography (Table VIII).

With the presence of up to 9 arginines and lysines one would expect 10-11 tryptic peptides. The tryptic fingerprint of the CBCam-IVCMI peak material is a pattern of seven consistently present fluorescamine positive spots (Figure 16). Of these only 5 peptides have been analyzed (Table IX), which contribute 25 of the total of about 80 residues. The $\mathrm{N}$-terminal arginine considered, there would be four or five quite 
Table IX

Amino acid composition and N-terminal amino acid residues for the tryptic peptides of the CBCamIVCM1 His/Arg-fragment mixture. The peptides were obtained from 5 plates with the pattern shown in Figure 16.

\begin{tabular}{ll} 
Peptide \\
\hline Q, R & Ser $_{1.0}, \operatorname{Thr}_{1.0}$, Glx $_{3.2}$, Gly $_{1.3}$, Ala $_{1.2}$, Ile $\left._{0.9}\right)$ \\
& Lys $_{1.0}$ \\
P & Asx $_{1.0}-\operatorname{Arg}_{1.0}$ \\
S & Ala $_{1.0}-\operatorname{Hse}_{0.9}$ \\
T & $\left(\operatorname{Trp}_{1}-\operatorname{Arg}_{1.0}\right.$ \\
U & Asx $_{0.6}\left(\right.$ Asx $_{1.0}$, Gly $_{1.3}$, Ile $_{0.6}$, Leu $_{2.1}$, His $\left._{1.1}\right)$ \\
& Arg \\
\hline
\end{tabular}

large and hydrophobic peptides not accounted for. Such peptides would be difficult to elute from the thin layer chromatograms, or remain at the origin. The peptide $T$ revealed only arginine in the amino acid analysis, but stained for tryptophan and did not yield an N-terminal amino acid. The chromatographic and electrophoretic properties were different from the amino acid marker arginine, which suggests the sequence Trp-Arg. The peptide $S$ must be at the C-terminus of one of the fragments since it contains homoserine and its lactone. The cadmium ninhydrin orange peptide below peptide $T$ was found in a partial amino acid analysis to contain aspartate (possibly asparagine) and the single residue of proline. The missing peptides could be those encircled with broken lines, the large size possibly interfering with the flourescamine staining as it is observed with the cadmium ninhydrin reagent (17). The peptide $P$ was slightly contaminated with peptide $\mathrm{R}$. This showed up in the amino acid composition and in the dansyl analysis, as the dansyl derivative of aspartic acid was contaminated with the serine derivative.

\subsection{Characterization of the fragments with $\mathrm{N}$ - terminal isoleucine and threonine}

In only one experiment this fragment has been isolated in reasonable purity (CBP-CM8). The amino acid composition of the fragment containing 25 residues is shown in Table X. Originally, this fragment was thought to be
Table X

Amino acid composition of fragments of the CB-V group. CBP-CM8 has an N-terminal isoleucine, whereas CBCam-V and CBCam-VSP2 contained an additional peptide with $\mathrm{N}$-terminal threonine.

\begin{tabular}{lccc}
\hline Amino acid & CBP-CM8 & CBCam-Va) & $\begin{array}{c}\text { CBCam- } \\
\text { VSP2a) }\end{array}$ \\
\hline Asx & 2.0 & 2.2 & 2.8 \\
Thr & 1.0 & 0.8 & 1.0 \\
Ser & 0.7 & 0.7 & 0.8 \\
Glx & 2.1 & 2.7 & 2.6 \\
Pro & 0.9 & 0.5 & 0.4 \\
Gly & 2.5 & 2.9 & 1.6 \\
Ala & 2.0 & 1.8 & 1.6 \\
Val & 2.6 & 2.2 & 2.0 \\
Ile & 1.7 & 1.6 & 1.6 \\
Leu & 2.2 & 1.9 & 2.0 \\
Tyr & - & - & - \\
Phe & 1.7 & 1.6 & 2.0 \\
His & 0.8 & 0.8 & 0.4 \\
Lys & 1.1 & 1.0 & 1.0 \\
Arg & 2.2 & 1.9 & 2.0 \\
Homoserine & & & \\
+ lactone & 1.0 & 0.8 & 0.8 \\
& & & \\
Yield & 150 nmoles & 500 nmoles & 50 nmoles \\
\hline
\end{tabular}

a) Values are based on comparison with the size and composition of CBP-CM8.

larger, about 45 residues long and having an internally uncleaved methionine peptide bond (42). The analysis of the histidine and arginine fragments (3.8) shows that this was an overestimation. Later attempts to purify this fragment have not been successful. Firstly, the yields from chromatography columns have been very low. Secondly, a fragment with $\mathrm{N}$-terminal threonine was now present with the isoleucine fragment throughout all attempts of purification. It is likely that more efficient $\mathrm{CNBr}$ fragmentation released the threonine fragment in the later attempts. The amino acid composition of the mixture of the two peptides is quite similar to the analysis of the pure isoleucine fragment (Table $X)$. It is therefore likely that only small amounts of the threonine fragment are present in the mixture.

The tryptic fingerprints shown in Figure 17 revealed 7 flourescamine positive spots. Of these, two did not reveal significant amounts of 


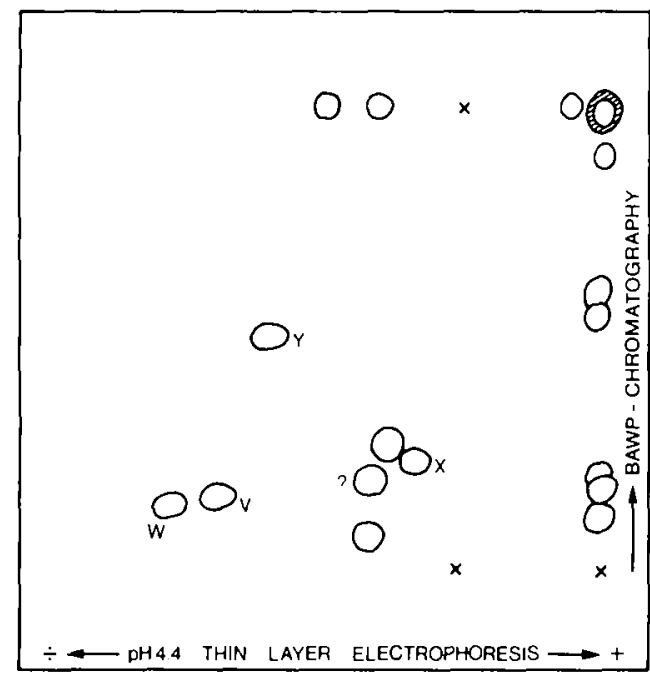

Figure 17. Tryptic fingerprint of fragments with $\mathrm{N}$ terminal isoleucine and threonine from the CBCamVSP2 pool. Three chromatograms were made and all plates stained with the fluorescamine reagent.

elutable peptide material. Four spots revealed a single peptide of good yield and stoichiometric composition. The fifth spot (W) contained two peptides. The compositions and $\mathrm{N}$-terminal amino acid residues are shown in Table XI. These peptides account for 20 out of the 40-50 residues in the two fragments. The $\mathrm{N}$-terminus of peptide $X$ was not determined. It could be glycine as the yield of this amino acid was quite low, possibly due to a high extent of fluorescamine modification.

\section{Table XI}

Amino acid composition and N-terminal amino acid residues of tryptic peptides obtained from the CBCam-VSP2 fragment mixture. The peptides were obtained from 3 plates with the pattern shown in Figure 17.

\begin{tabular}{|c|c|}
\hline & \\
\hline V & Ala $_{1.0}-\operatorname{Arg}_{1.0}$ \\
\hline W & Ile $_{0.8}$ and Gly $_{0.6}$. (Lys 1.0, Arg1.0) \\
\hline ? & $\operatorname{Ser}_{1.0}\left(\mathrm{Glx}_{0.7}, \mathrm{Gly}_{1.0}\right)$ \\
\hline $\mathrm{X}$ & 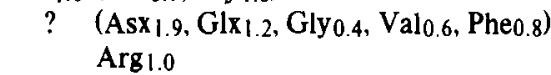 \\
\hline Y & 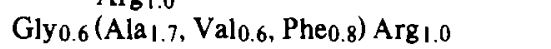 \\
\hline
\end{tabular}

The peptide marked with ? contained only serine, glutamate and glycine, probably arisen by unspecific cleavage. However, the existence of this peptide is mysterious since the trypsin is not likely to split after any of these residues. No signs of contamination with other protease activities were observed, apart from a chymotrypsin-like activity - known for trypsin itself (41) - with the Pro-fragment (cf. Table V).

A peptide containing $\mathrm{N}$-terminal threonine was not isolated. Furthermore, a peptide containing homoserine and its lactone was not observed. Accordingly, the amount of information concerning the threonine fragment is still quite limited, but the consistent presence of this fragment during the experiments with the CBCamfragments is best explained by it being the tenth cyanogen bromide fragment.

\subsection{Characterization of the Pro-fragment of 2,000 dalton and the Lys-fragment of 1,500 dalton}

Table XII shows the amino acid composition of the purified Pro-fragment and Figure 18 presents the total amino acid sequence comprising 17 residues obtained in part by manual Edman degradation. Also given in Table XII is the amino acid composition of the Pro- and Lysfragment mixture of the CBP-VI peak. As judged by similar intensities of PTH-derivatives, dansylderivatives, and similar recoveries of the amino acids of HI-reconverted derivatives from individual Edman degradation cycles during sequencing from the $\mathrm{N}$-terminal end of the mixture (Figure 19), the two fragments were present in approximately equimolar amounts. This permitted to deduce the N-terminal amino acid sequence of the lysine fragment by subtracting the sequence of the proline fragment (cf. Figure 19). The amino acid composition of the lysine fragment could likewise be obtained by subtraction (Table XII).

Tryptic peptide analysis of the CBP-VI fragment mixture resulted in five peptides listed in Figure 19. One of these corresponded to the entire Pro-fragment. The other four therefore derive from the Lys-fragment. As can be seen from their composition in Figure 19 they comprise two pairs of homologous peptides. In 
Table XII

Amino acid composition of CB-VI fragments having N-terminal proline and lysine. CBP-CM3 contains a single peptide with $\mathbf{N}$-terminal proline. CBP-VI contains an additional peptide with $\mathrm{N}$-terminal lysine.

\begin{tabular}{lccc}
\hline & CBP-VI & $\begin{array}{c}\text { CBP-CM3a) } \\
\text { CBCam-VISP1 } \\
\text { CBCam-VISP2b) }\end{array}$ & (CBP-VI)-(CBP-CM3) \\
\hline Asx & 2.0 & - & 2.0 \\
Thr & - & - & - \\
Ser & 0.8 & 0.8 & - \\
Glx & 1.2 & - & 1.2 \\
Pro & 1.6 & 1.6 & - \\
Gly & 4.0 & 3.0 & 1.0 \\
Ala & 2.1 & 1.0 & 1.1 \\
Val & 3.0 & 2.2 & 0.8 \\
Ile & 2.2 & 1.4 & - \\
Leu & 0.2 & - & - \\
Tyr & 0.1 & - & 1.4 \\
Phe & 0.2 & 1.4 & 1.0 \\
His & 2.8 & - & 1.2 \\
Lys & 1.0 & - & 0.8 \\
Arg & 1.2 & 1.0 & \\
Homoserine + lactone & 1.8 & & \\
\hline
\end{tabular}

a) The final yield of CBP-CM 3 was 500 nmoles out of $2.8 \mu$ moles, corresponding to $18 \%$.

b) The yield of CBCam-VISP $1+2$ was 290 nmoles out of 2.5 moles, i.e. $12 \%$.

Figure 18. The amino acid sequence of fragment CBP-CM3 with $\mathrm{N}$-terminal proline. The sequencing (cf. 2.9) stopped after the valine at position 13. The rest of the sequence was obtained by isolation of the peptides after digestion of CBP-CM 3 with $\alpha$-chymotrypsin and subtilisin. The chymotryptic peptides were separated on a 0.9 $\times 130 \mathrm{~cm}$ column of Bio-Gel P4 (cf. 2.11 ) with $0.1 \mathrm{M}$-ammonium bicarbonate and $1 \mathrm{ml}$ fractions collected. Five peaks were observed. Two large peptides had the same amino acid composition, but different $280 \mathrm{~nm}$ absorption, the ratio being about 2:1. The other three peaks contained the two small peptides and free tryptophan. The peptides were identified by amino acid composition, absorption at $280 \mathrm{~nm}$ and staining reactions on silicagel thin layers. The subtilisin derived peptides and free alanine were isolated from two dimensional silicagel thin layer chromatograms (cf. 2.11) after fluorescamine staining. Of particular interest are the two peptides giving only valine in the amino acid analysis as well as dansyl-analysis but having different chromatographic properties indicating the presence of one and two tryptophan residues respectively.

Figure 19. Amino acid sequences of two CNBr fragments in the CBP-VI fragment mixture (cf. Figure 2), and amino acid compositions of peptides from tryptic digests of these fragments obtained from the large subunit of ribulose bisphosphate carboxylase of barley and spinach. The CNBr-fragments were subjected to manual Edman-degradation. The tryptic peptides were separated on a $0.9 \times 130$ column of Bio-Gel P-4 (cf. 2.11) and 1 $\mathrm{ml}$ fractions collected. $100 \mu \mathrm{l}$ aliquots were removed from alternate fractions, dried and successively dissolved in $5 \mu \mathrm{l}$ of $0.05 \mathrm{M}$-pyridine acetate $\mathrm{pH} 2.45$ and applied to $10 \times 20 \mathrm{~cm}$ sheets of precoated silicagel thin layers. The spots were applied in series, $1 \mathrm{~cm}$ from one of the long edges and $0.5 \mathrm{~cm}$ apart. Ascending chromatography was run along the short edges using solvent $\mathrm{A}$ (cf. 2.11). The thin layers were stained with the cadmium ninhydrin reagent or sprayed with the fluorescamine reagent. Samples from appropriate fractions or fluorescamine positive peptide spots were used for amino acid analysis and $\mathrm{N}$-terminal determinations (cf. 2.12). 
C. PouLsen: Cyanogen bromide fragments of ribulosebisphosphate carboxylase

CBP- $\mathrm{CM} 3$

Chymotrypsin

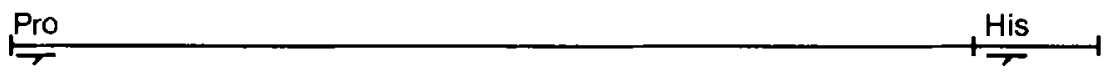

Pro

Subtilisin

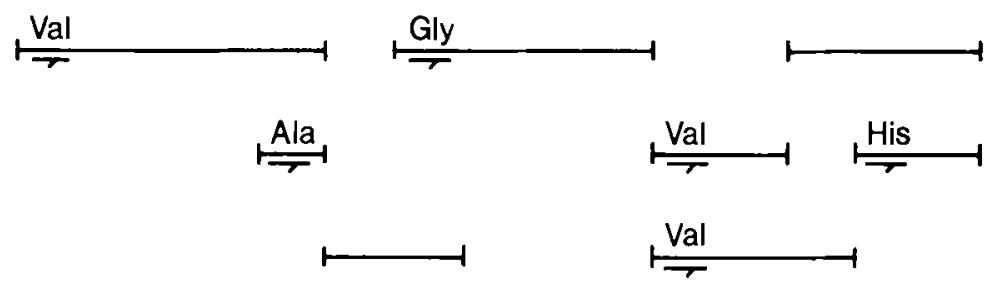

Large Subunit

CBP-II $(\longrightarrow, \mathrm{HI} ; \longrightarrow$, Dansyl; $\longrightarrow$, PTH $)$

Fig. 19

Barley

Pro - Gly - Val - Ile - Pro - Val - Ala -

$\mapsto \vec{\rightarrow} \rightarrow \vec{\rightarrow} \rightarrow \vec{\rightarrow}$

(Ser, Pro $_{2}$, Gly $_{3}, \mathrm{Ala}, \mathrm{Val}_{3}, \mathrm{Ile}_{2}, \mathrm{His}_{2}$, Trp ) Hse

Lys - Ala - Val - Ile - Asp - His - Arg - Gln -

$\vec{\rightarrow} \rightarrow \vec{\rightarrow} \rightarrow \vec{\rightarrow} \rightarrow \vec{r}$

Lys (Ala, Val, lle, Asx, His) Arg

(Glx, Asx, Gly, His, Lys) Hse

Ala (Val, lle, Asx, His) Arg

(Asx,Gly,His) Hse

Spinach

Lys - Ala - Val - Ile - Asx - His - Arg-Glx-

$\mapsto \rightarrow \vec{\rightarrow} \rightarrow \vec{\rightarrow} \rightarrow \vec{r}$

Lys (Ala, Val, lle, Asx, His) Arg

Ala(Val, lle, Asx, His)Arg

(Glx, Asx, Gly, His, Lys) Hse

His - Arg - Ala - Val - Phe - Ala - Arg - Glx -

$r \rightarrow \vec{r} \rightarrow \vec{r}$

His - Arg

$r$

Ala(Val, Phe, Ala, Arg) (Glx, Gly, Pro, Val 2, Ile, Leu) Hse

Carlsberg Res. Commun. Vol. 44, p. 163-189, 1979 
one pair trypsin has not cleaved after lysine, in the other it has. 13 amino acids can be accounted for, whereas the amino acid analysis (Table XII) shows one lysine residue less.

\subsection{Characterization of two spinach large subunit cyanogen bromide fragments}

CNBr-fragments from S-4-pyridylethylated spinach large subunit were subjected to gel filtration on Bio-Gel P-30 and the last peak containing the two smallest fragments were analyzed in parallel to the barley CBP-VIfragment mixture (cf. 3.10). Approximate equimolarity was observed for the two spinach fragments in this mixture. Edman degradation and tryptic peptide analysis revealed one fragment to be identical to the barley lysine-fragment (Figure 19). The other fragment was homologous to the isoleucine fragment of barley (CBPCM8), which by automatic Edman degradation was shown to have the following N-terminal sequence (29): Ile-Lys-Gly-Ala-Val-Phe-AlaArg-Gin-Leu-Gly-Val-Pro-Glu-

The spinach fragment has at the same positions:
Met-His-Arg-Ala-Val-Phe-Ala-Arg-Glx-

The tryptic peptides of the fragment (Figure 19) contained as additional amino acids Glx, Leu, Gly, Val, Pro, which can be found in the barley sequence, but also $\mathrm{Val}$, Ile and Met as yet not accountable for in the barley fragment. Three amino acid replacements and a difference in the positioning of the methionines is thereby established between the spinach and barley large subunit.

\section{DISCUSSION}

Cyanogen bromide cleavage of the large subunit of barley ribulosebisphosphate carboxylase resulted in nine out of ten expected fragments (Table XIII). A tenth fragment was indicated in one cleavage experiment. It had a terminal threonine and was inseperable from the Ile-fragment. Since the Pro-fragment of 10,000 dalton has a counterpart with a lower apparent molecular weight but identical N-terminal sequence, it is likely that the threonine fragment is the terminal part of the Pro-fragment of 10,000

Table XIII

Accounting for the amino acid composition of the large subunit by adding up the approximate amino acid composition of the 9 cyanogen bromide fragments.

\begin{tabular}{lccccccccc}
\hline Fragment & Ala & Pro & PyrGin & Ser & His/Arg & lle & Pro & Lys & Sum \\
\hline Asx & 11 & 8 & 5 & 6 & 7 & 2 & - & 2 & 41 \\
Thr & 13 & 5 & 5 & 3 & 6 & 1 & - & - & 33 \\
Ser & 6 & 3 & 2 & 2 & $1-2$ & 1 & 1 & - & $16-17$ \\
Glx & 17 & 11 & 9 & 4 & 8 & 2 & - & 1 & 52 \\
Pro & 10 & 5 & 1 & - & 1 & 1 & 2 & - & 20 \\
Gly & 11 & 9 & 7 & 7 & $7-9$ & 2 & 3 & 1 & $47-49$ \\
Ala & 14 & 13 & 9 & 3 & $8-10$ & 2 & 1 & 1 & $51-53$ \\
Val & 11 & 6 & 2 & 4 & $2-3$ & 3 & 3 & 1 & $32-33$ \\
Ile & 4 & 4 & 3 & 3 & $3-4$ & 2 & 2 & 1 & $22-23$ \\
Leu & 9 & 6 & 4 & 5 & 7 & 2 & - & - & 33 \\
Tyr & 10 & 3 & 3 & 1 & 4 & - & - & - & 21 \\
Phe & 3 & 3 & 3 & 4 & 4 & 2 & - & - & 19 \\
His & $1-2$ & 1 & 2 & 2 & 4 & 1 & 2 & 2 & $15-16$ \\
Lys & 5 & 4 & 4 & 2 & 3 & 1 & - & $1-2$ & $20-21$ \\
Arg & 4 & 4 & 4 & 4 & $5-6$ & 2 & - & 1 & $24-25$ \\
Met & 1 & $(1)$ & 1 & 1 & 2 & 1 & 1 & 1 & 9 \\
Trp & $(2-3)$ & $(2-3)$ & $(1)$ & $(1)$ & $(1)$ & - & $(1-2)$ & - & $8-11$ \\
Cys & $2-3$ & $2-3$ & - & - & 3 & - & - & $(0-1)$ & $7-10$ \\
\hline Sum & $134-137$ & $90-92$ & 65 & 52 & $76-85$ & 25 & $16-17$ & $13-14$ & $471-487$ \\
\hline
\end{tabular}


dalton. The latter does not contain homoserine and its lactone. It is therefore considered to be the C-terminal fragment.

Eight of the nine in Table XIII listed CNBrfragments have been shown by automatic sequencing to have unique $\mathrm{N}$-terminal sequences in the following paper (29), where it is also proven that the Ala-fragment of 15,000 dalton is the $\mathrm{N}$-terminal fragment of the large subunit. The ninth N-terminally blocked PyrGin-fragment is characterized by peptide mapping (3.7). There is no combinations of two or more fragments which could give rise to anyone of the nine peptides listed in Table XIII. The approximated whole number amino acid compositions for the individual $\mathrm{CNBr}$-fragments are summarized in this Table. After summation of the numbers most of the amino acids are close to the composition of the intact large subunit (Table I), being a little too low in the case of aspartic acid, serine, proline and phenylalanine, and a little too high in the case of threonine, glutamic acid and alanine. These differences can be more or less explained by the deviations from the correct number in the individual analyses. The excess of tyrosine could in part be due to partial destruction in the original analyses of the large subunit, as it was occasionally observed in some of the analyses of the $\mathrm{CNBr}$-fragments. What is not easily explained, is the relatively low yields of leucine, lysine and arginine.

The tryptic peptide analyses of the $\mathrm{CNBr}$ fragments have not revealed similarities between the fingerprints. Only a single peptide has been identified in more than one fingerprint, namely Gly-Arg in the B peptide of the Ala-fragment and in one of the $W$ peptides of the Ile-fragment. This peptide is so short that the duplication has no meaning. This provides an additional indication of the individuality of the nine fragments.

The yields of the analyzed tryptic peptides were in the region of 2-5 nanomoles, which was far less than what was applied to the cellulose thin layers. However, the elution of large quantities of undigested peptide material suggested, that the trypsin only to a limited extent attacked the $\mathrm{CNBr}$-fragments. The sequence analyses of the CNBr-fragments (29) and the sequences published by HARTMAN et al. (12) have revealed that a considerable number of the arginines and lysines is followed either by the acidic amino acids or by proline, which could be the reason for the limited attack by trypsin.

It has been observed that ion-exchange chromatography has a tendency to split the elution of a particular fragment into two peaks. This was not observed by FowLER (8) in the analyses of the $\mathrm{CNBr}$-fragments from $\beta$-galactosidase. With the barley ribulosebisphosphate carboxylase $\mathrm{CNBr}$-fragments exponential gradients rather than linear gradients were used for elution. Since the exponential gradient improves spreading of the peptides and sharpens the peaks, it is suggested that the single charge difference represented by homoserine versus homoserinelactone is exploited with the exponential gradient, homoserine being negatively charged above pH 4 and its lactone being neutral.

\section{ACKNOWLEDGEMENT}

The help and encouragement provided by Dr. A. A. HoLDER through valuable discussions and kind suggestions is gratefully acknowledged. Ms. Bodil Corneliussen, Ms. Lone Sørensen and the staff of the Chemistry Department, Carlsberg Laboratory is thanked for the amino acid composition determinations.

\section{REFERENCES}

1. Beaven, G. H. \& E. R. Holiday: Ultraviolet absorption spectra of proteins and amino acids. Adv. Protein Chem. 7, 219-386 (1952)

2. Bencze, W. L. \& K. SCHmid: Determination of tyrosine and tryptophane in protein. Anal. Chem. 29, 1193-1196 (1957)

3. Bennet, J. C.: Paper chromatography and electrophoresis: special procedure for peptide maps. In: Methods on Enzymology, C. H. W. Hirs, ed., Academic Press, New York and London, Vol XI pp. 330-339 (1967)

4. Bl.AIR, G. E. \& R. J. Ellos: I. Light-driven synthesis of the large subunit of Fraction I protein by isolated pea chloroplasts. Biochem. Biophys. Acta 319, 223-234 (1973)

5. Chan, P. H. \& S. G. Wildman: Chloroplast DNA codes for the primary structure of the large subunit of Fraction I protein. Biochem. Biophys. Acta $277,677-680$ (1972)

6. Chun, N.-H. \& P. Bennoun: Thylakoid membrane polypeptides of Chlamydomonas reinhardti: Wild type and mutant strains deficient in 
photosystem II reaction center. Proc. Nat. Acad. Sci. U.S.A. 72, 2175-2179 (1975)

7. Coen, D. M., J. R. Bedbrook, L. Bogorad \& A. RıCH: Maize chloroplast DNA fragment encoding the large subunit of ribulose bisphosphate carboxylase. Proc. Nat. Acad. Sci. U.S.A. 74, 5487-549I (1977)

8. Eastey, C. W.: Combinations of specific color reactions useful in the peptide mapping technique. Biochim. Biophys. Acta 107, 386-388 (1965)

9. Elus, R. J.: Fraction I protein. Comm. Plant. Science 4, 29-33 (1973)

10. Fowler, A.: Amino acid sequence of $\beta$ galactosidase VIII. Isolation of the 24 cyanogen bromide peptides. J. Biol. Chem. 253, 54995504 (1978)

I1. Friedman, M., L. H. Krull \& J. F. Cavins: The chromatographic determination of cystine and cysteine residues in proteins as S- $\beta-(4-$ pyridylethyl)-cysteine. J. Biol. Chem. 245, 3868-3871 (1970)

12. Gelvin, S., P. Heizmann \& S. H. Howell: Identification and cloning of the chloroplast gene coding for the large subunit of ribulose bisphosphate carboxylase from Chlamydomonas reinhardi. Proc. Nat. Acad. Sci. U.S.A. 74. 31933197 (1977)

13. HaRTLEY, B. S.: Strategy and tactics in protein chemistry. Biochem. J. 119, 805-822 (1970)

14. Hartman, F. C., I. L. Norton, C. D. Stringer \& J. V. Schloss: Attempts to apply affinity labeling techniques to ribulosebisphosphate carboxylase/oxygenase. In: Photosynthetic carbon assimilation, H. W. Siegelman \& G. Find eds., Plenum Press, New York and London, pp. 245269 (1978)

15. Herrman, R. G., H. J. Bohnert, E. J. Crouse, A. J. Driesel. J. M. Schmitt \& K. Gordon: Physical mapping and localization of genes on Spinacia and Oenothera chloroplast DNA. Hoppe-Seyler's Z. Physiol. Chem. 360, 281 (1979)

16. HiRs, C. H. W.: Reduction and S-carboxymethylation of protein. In: Methods in Enzymology, C. H. W. Hirs ed., Academic Press, New York and London, Vol. XI pp. 199-203 (1967)

17. Holder, A. A.: Peptide mapping of the ribulose bisphosphate carboxylase large subunit from the genus Oenothera. Carlsberg Res. Commun. 43, 391-399 (1978)

18. Inglis, A. S., P. W. Nichols \& C. M. RoxBURGH: Acid hydrolysis of phenylthiohydantoins of amino acids. Aust. J. Biol. Sci. 24. 12471250 (1971)

19. Jacobsen, H., A. Demandt, A. J. Moody \& F.
SundBY: Sequence analysis of porcine gut GLI-1. Biochim. Biophys. Acta 493, 452-459 (1977)

20. Jende-Strid, B.: Mutations affecting flavonoid synthesis in barley. Carlsberg Res. Commun. 43, 265-273 (1978)

21. Kawashima, N. \& S. G. Wildman: Studies on Fraction I protein. IV. Mode of inheritance of primary structure in relation to whether chloroplast or nuclear DNA contains the code for a chloroplast protein. Biochim. Biophys. Acta 262, 42-49 (1972)

22. Kung, S. D.: Tobacco Fraction I protein: A unique genetic marker. Science 191, 429-434 (1976)

23. Mendez, E. \& C. Y. LAI: Reactions of peptides with fluorescamine on paper after chromatography or electrophoresis. Analytical Biochemistry 65, 281-292 (1975)

24. Narita, K.: End group determination: In: Protein Sequence Determination, S. B. Needleman ed., Springer-Verlag, Berlin-HeidelbergNew York (1970)

25. NevilLe, Jr., D. M.: Molecular weight determination of protein-dodecyl sulfate complexes by gel electrophoresis in a discontinuous buffer system. J. Biol. Chem. 246, 6328-6334 (1971)

26. Peterson, J. D., S. Nehrlich, P. E. Oyer \& D. SteINER: Determination of the amino acid sequence of the monkey, sheep and dog proinsulin C-peptides by a semi-micro Edman degradation procedure. J. Biol. Chem. 247, 4866-4871 (1972)

27. Podell, D. N. \& G. N. Abraham: A technique for the removal of pyroglutamic acid from the amino terminus of proteins using calf liver pyroglutamate amino peptidase. Biochem. Biophys. Res. Commun. 81, 176-185 (1978)

28. Poulsen, C.: Studies on the primary structure of D-ribulose-1,5-diphosphate carboxylase. Cand. Scient. Thesis, Copenhagen Liniversity (1977)

29. Poulsen, C., B. Martin \& I. Svendsen: Partial amino acid sequence of the large subunit of ribulosebisphosphate carboxylase from barley. Carlsberg Res. Commun. 44, 191-199 (1979)

30. Poulsen, C., S. Strgbek \& B. G. Hasiett: Studies on the primary structure of the small subunit of ribulose-1,5-diphosphate carboxylase. In: Genetics and biogenesis of chloroplast and mitochondria, Th. Bücher et al. eds., Elsevier/ North Holland, Biomedical Press, Amsterdam, the Netherlands pp. 17-24 (1976)

31. Sakano, K., S. D. Kung \& S. G. Wildman: Identification of several chloroplast DNA genes, which code for the large subunit of Nicotiana Fraction I protein. Molec. gen. Genet. 130, 9197 (1974) 
32. Schiltz, E. \& J. Rheinbolt: Determination of the complete amino acid sequence of protein S-4 from Escherichia coli ribosomes. Eur. J. Biochem. 56, 467-481 (1975)

33. SCOWCROFT, W. R.: Nucleotide polymorphism in chloroplast DNA of N. debneyi. Theor. Appl. Genet. (1979) in press

34. Smithies, O., D. Gibson, E. M. Fanning, R. M. Goodfliesh, J. G. Gilman \& D. L. Ballantyne: Quantitative procedures for use with the EdmanBegg sequenator. Partial sequences of two unusual immunoglobulin chains, Rzf and Sac. Biochemistry 10, 4912-4921 (1971)

35. Steers, E., G. R. Croven \& C. B. Anfinsen: Evidence for nonidentical chains in the $\beta$ galactosidase of E. coli K 12, J. Biol. Chem. 240, 2478-2484 (1965)

36. Strbbek, S., G. C. Gibbons, B. Haslett, D. BOULTER \& S. G. WiLDMaN: On the nature of the polymorphism of the small subunit of ribulose-1,5-diphosphate carboxylase in the amphidiploid Nicotiana tabacum. Carlsberg Res. Commun. 41, 335-344 (1976)

37. Summers, M. R., G. W. Smythers \& S. OROSZLAN: Thin layer chromatography of subnanomole amounts of phenylthiohydantoins (PTH) amino acids on polyamide sheets. Analytical Biochemistry 53, 624-628 (1973)
38. TAKabE, T. \& T. AKaZaWA: Molecular evolution of ribulose-1,5-bisphosphate carboxylase. Plant and Cell Physiol. 16, 1049-1060 (1975)

39. Tang, J., P. Sepulveda, J. Marciniszyn Jr., K. C. S. Chen, W.-Y. Huang, N. TaO, D. Liu \& J. P. LANIER: Amino acid sequence of porcine pepsin. Proc. Nat. Acad. Sci. U.S.A. 70, 34373439 (1973)

40. UChimiya, H. \& S. G. Wildman: Evolution of Fraction 1 protein in relation to origin of amphidiploid Brassica species and other members of the Cruciferae. J. Heredity 69, 299-303 (1978)

41. Walsh, K. A.: Trypsinogens and trypsins of various species. In: Methods in Enzymology, G. E. Pearlman \& L. Lorand eds., Academic Press, New York and London, Vol. XIX pp. 41-63 (1970)

42. Wettstein, D. von, C. Poulsen \& A. A. HolDER: Ribulose-1,5-bisphosphate carboxylase as a nuclear and chloroplast marker. Theor. Appl. Genet. 53, 193-197 (1978)

43. Wildman, S. G. \& P. Kwanyuen: Fraction I protein and other products from tobacco for food. In: Photosynthetic carbon assimilation, $\mathrm{H}$. W. Siegelman \& G. Hind eds., Plenum Press, New York and London, pp. 1-18 (1978) 